\title{
RMetS
}

Royal Meteorological Society

\section{The water vapour intercomparison effort in the framework of the Convective and Orographically-induced Precipitation Study: airborne-to-ground-based and airborne-to-airborne lidar systems}

R. Bhawar, ${ }^{\text {a }}$ P. Di Girolamo, ${ }^{\text {a* }}$ D. Summa, ${ }^{\mathrm{a}}$ C. Flamant,${ }^{\mathrm{b}}$ D. Althausen, ${ }^{\mathrm{c}}$ A. Behrendt, ${ }^{\mathrm{d}}$ C. Kiemle, ${ }^{\mathrm{e}}$ P. Bosser, ${ }^{\mathrm{f}}$ M. Cacciani, ${ }^{\mathrm{g}}$ C. Champollion, ${ }^{\mathrm{b}}$ T. Di Iorio, ${ }^{\mathrm{g}}$ R. Engelmann, ${ }^{\mathrm{c}}$

C. Herold, ${ }^{\mathrm{c}}$ D. Müller, ${ }^{\mathrm{c}}$ S. Pal, ${ }^{\mathrm{d}}$ M. Wirth ${ }^{\mathrm{e}}$ and V. Wulfmeyer ${ }^{\mathrm{d}}$

${ }^{a}$ Dipartimento di Ingegneria e Fisica dell'Ambiente, Università degli Studi della Basilicata, Potenza, Italy

${ }^{\mathrm{b}}$ Laboratoire Atmosphères, Milieux, Observations Spatiales, CNRS-UPMC, Paris, France

${ }^{c}$ Leibniz Institute for Tropospheric Research, Leipzig, Germany

${ }^{\mathrm{d}}$ Institut für Physik und Meteorologie, Universität Hohenheim, Stuttgart, Germany

${ }^{\mathrm{e}} D L R$ - Institut für Physik der Atmosphäre, Oberpfaffenhofen, Wessling, Germany

${ }^{\mathrm{f}}$ LOEMI - Institut Géographique National, Saint-Mandé, France, now at DPTS - École Nationale des Sciences Géographiques, Marne-La-Vallée, France

'Dipartimento di Fisica, Università degli Studi di Roma 'La Sapienza', Rome, Italy

${ }^{*}$ Correspondence to: P. Di Girolamo, Dipartimento di Ingegneria e Fisica dell’Ambiente - DIFA, Università degli Studi della Basilicata, Viale dell'Ateneo Lucano n. 1085100 Potenza Italy. E-mail: digirolamo@unibas.it

An intensive water vapour intercomparison effort, involving airborne and groundbased water vapour lidar systems, was carried out in the framework of the COPS experiment. The main objective of this paper is to provide accurate error estimates for these systems.

Comparisons between the ground-based Raman lidar BASIL and the airborne CNRS DIAL (Differential Absorption Lidar) indicate a mean relative bias between the two sensors, calculated with respect to the mean value of $-2.13 \%\left(-0.034 \mathrm{~g} \mathrm{~kg}^{-1}\right)$ in the altitude region $0.5-3.5 \mathrm{~km}$, while comparisons between BASIL and the airborne DLR DIAL lead to a mean relative bias of $1.87 \%\left(0.018 \mathrm{~g} \mathrm{~kg}^{-1}\right)$ in this same altitude region.

Comparisons between the ground-based UHOH DIAL and the CNRS DIAL indicate a bias of $-3.2 \%\left(-0.37 \times 10^{22} \mathrm{~m}^{-3}\right)$ in the altitude range $1.5-4.5 \mathrm{~km}$, while comparisons between the UHOH DIAL and the DLR DIAL indicate a bias of $0.83 \%\left(0.06 \times 10^{22} \mathrm{~m}^{-3}\right)$ in this same altitude range. Based on the available comparisons between the groundbased Raman lidar BERTHA and the CNRS DIAL, the mean relative bias is found to be $-4.37 \%\left(-0.123 \mathrm{~g} \mathrm{~kg}^{-1}\right)$ in the altitude region $0.5-4.5 \mathrm{~km}$. Comparisons between the ground-based IGN Raman lidar and the CNRS DIAL indicate a bias of 3.18\% $\left(0.55 \mathrm{~g} \mathrm{~kg}^{-1}\right)$ in the altitude range from 0.5 to $4.5 \mathrm{~km}$, while comparisons between the CNRS DIAL and DLR DIAL result in a mean relative bias of $3.93 \%\left(1.1 \times 10^{22} \mathrm{~m}^{-3}\right)$ in the altitude interval $0.5-4.0 \mathrm{~km}$. Based on the available statistics of comparisons, benefiting from the fact that the CNRS DIAL was able to be compared with all other lidar systems, and putting equal weight on the data reliability of each instrument, overall relative values for BASIL, BERTHA, IGN Raman lidar, UHOH DIAL, DLR DIAL, and CNRS DIAL, with respect to the mean value, are found to be $-0.38,-2.60,4.90,-1.43$, -2.23 and $1.72 \%$, respectively. Copyright (C) 2011 Royal Meteorological Society

Key Words: $\quad$ water vapour; DIAL; Raman lidar; bias; root-mean-square deviation

Received 24 February 2010; Revised 3 August 2010; Accepted 6 August 2010; Published online in Wiley Online Library 6 January 2011

Citation: Bhawar R, Di Girolamo P, Summa D, Flamant C, Althausen D, Behrendt A, Kiemle C, Bosser P, Cacciani M, Champollion C, Di Iorio T, Engelmann R, Herold C, Müller D, Pal S, Wirth M, Wulfmeyer V. 2011. The water vapour intercomparison effort in the framework of the Convective and Orographicallyinduced Precipitation Study: airborne-to-ground-based and airborne-to-airborne lidar systems. Q. J. R. Meteorol. Soc. 137: 325-348. DOI:10.1002/qj.697 


\section{Introduction}

High-quality water vapour observations are vitally important for most key areas of atmospheric sciences. For example, predicting the initiation of deep convection in a cloudresolving model is highly dependent on the availability of accurate estimates of water vapour data within and just above the boundary layer (e.g. Crook, 1996; Kottmeier et al., 2008). Furthermore, once deep convection develops, reliable measurements of the vertical profile of water vapour are of first-order importance in the prediction of precipitation rates, since water vapour is directly involved in a variety of thermodynamic and microphysical processes. Unfortunately, despite its importance, current observational techniques for measuring tropospheric water vapour present biases often not better than 10\% (among others, Barnes et al., 2008; Suortti et al., 2008).

Lidar systems based on the application of the Differential Absorption Lidar (DIAL) and Raman techniques have the potential to fill the observational gaps left by conventional observation systems by providing water vapour profiles with high vertical resolution and low bias, covering a substantial portion of the troposphere. The present work aims at providing error estimates for the water vapour profiles measured by different water vapour lidars based on an intensive intercomparison effort. Comparisons between airborne DIAL and ground-based Raman lidars have already been reported in the literature (Whiteman et al., 2006; Behrendt et al., 2007a,b). The papers by Behrendt et al.report on the largest intercomparison effort between water vapour lidar systems performed so far, which was conducted in the frame of the IHOP_2002 project (Weckwerth et al., 2004). The IHOP_2002 intercomparison study involved four lidar systems (three airborne, one ground-based) and chilledmirror radiosondes. In the present paper, we report on the intercomparison results obtained in the framework of COPS, which involved a larger number of lidars, namely six (three DIALs, three Raman lidars; four ground-based lidars, two airborne lidars) with lidar-to-lidar intercomparisons extending to higher altitudes than previously. Simultaneous and co-located data from ground-based and airborne lidars have been used to compute relative bias and root-meansquare (RMS) deviations as a function of altitude. We also provide a preliminary estimate of the impact on the reduction of the overall measurement error in water vapour profiling based on the synergetic use of information coming from different lidars.

The airborne lidars provide two-dimensional (2D) measurements (profiles along a horizontal transect) of atmospheric water vapour, while the vertical-pointing ground-based lidars provide time-evolving one-dimensional (1D) measurements (profiles at one single location). Comparisons of data from these two types of lidar have the potential to assess the representativeness error of groundbased lidars, i.e. to answer the question 'How representative are $1 \mathrm{D}$ profiles for a certain region in a given meteorological situation?' This aspect, addressed in this manuscript only marginally, will be the topic of a forthcoming paper.

The paper outline is the following. Section 2 provides brief information on the COPS experiment and its observation strategy. In section 3, we provide a short description of the lidar systems involved in this effort, including information on the lidar system uncertainty in terms of both random and systematic errors. Section 4 describes the criteria we used to identify possible intercomparison cases between the lidar instruments and to define the intercomparison tables. Section 5 describes the algorithms used to compare the measurements from different lidars and to estimate bias and root-mean-square deviations as a function of altitude for each pair of instruments. Section 6 illustrates and discusses the intercomparison results for the different pairs of lidars. The results are summarized in section 7 , which also provides concluding remarks.

\section{COPS and the Supersites}

Measurements reported in this paper were collected during the Convective and Orographically-induced Precipitation Study (COPS). COPS was held in southwestern Germany and eastern France during the period 1 June-31 August 2007, as a Research and Development Project of the World Weather Research Programme (WWRP) (Wulfmeyer et al., 2008, 2011). COPS was conceived with the overarching goal of advancing the quality of forecasts of orographically-induced convective precipitation by fourdimensional observations and modelling of its life cycle. In order to achieve this goal, observations of the whole life cycle of convective precipitation, from the preconvective environment, to the initiation of convection, the formation and development of clouds and the development and decay of precipitation, have been carried out based on the synergy of state-of-the-art atmospheric research sensors. The uniqueness of the COPS experiment is represented by the simultaneous operation of a large collection of advanced ground-based and airborne passive and active remote sensing systems in combination with conventional in situ sensors. COPS was conducted together with the WWRP Forecast and Demonstration Project DPHASE (Demonstration of Probabilistic Hydrological and Atmospheric Simulation of flood Events: Rotach et al., 2009). Data collected during COPS represent a unique dataset for the assimilation (Wulfmeyer et al., 2006) and validation of mesoscale models. It is expected that the exploitation of this dataset will lead to an improved in-depth process understanding and modelling (e.g. Behrendt et al., 2011, Bennett et al., 2011, Corsmeier et al., 2011, and Chaboureau et al., 2011).

COPS is the most recent in a series of field experiments dedicated to the improvement of quantitative precipitation forecasting $(\mathrm{QPF})$ in different weather regimes, including the Mesoscale Alpine Programme (MAP: Rotunno and Houze, 2007), IHOP_2002 (Weckwerth et al., 2004), the Convective Storm Initiation Project (CSIP: Browning et al., 2007), and the COPS-pre-campaign Prediction, Identification and Tracking of Convective Cells (PRINCE: Groenemeijer et al., 2009).

A careful verification of the data quality of the involved instruments is essential for the success of any measurement campaign. This is especially true for large field efforts where the latest generation of state-of-the-art instruments and novel measurement techniques are employed. In addition to internal quality control and careful calibration, independent measurements of individual atmospheric parameters from different sensors must be compared with each other in order to ensure a consistent dataset and to provide accurate error estimates for all systems. In this respect, the COPS dataset represents a unique opportunity to intercompare data from a large variety of state-of-the-art atmospheric sensors. 


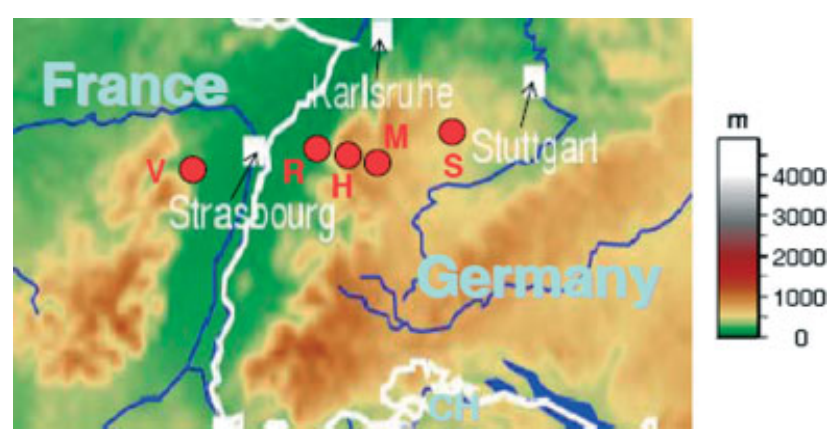

Figure 1. Region selected for COPS. The red dots represent the locations of the five supersites. From left to right: Vosges Mountains (V, $7.545^{\circ} \mathrm{E}$ $48.443^{\circ} \mathrm{N}$, elev. $150 \mathrm{~m}$ a.s.l.), Rhine Valley (R, Achern, $8.066^{\circ} \mathrm{E}, 48.638^{\circ} \mathrm{N}$ elev. $140 \mathrm{~m})$, Hornisgrinde Mountain $\left(\mathrm{H}, 8.204^{\circ} \mathrm{E}, 48.604^{\circ} \mathrm{N}\right.$, elev. $1150 \mathrm{~m})$, Murg Valley (M, $8.405^{\circ} \mathrm{E}, 48.545^{\circ} \mathrm{N}$, elev. $\left.500 \mathrm{~m}\right)$, Stuttgart $\left(\mathrm{S}, 8.813^{\circ} \mathrm{E}, 48.635^{\circ} \mathrm{N}\right)$.

As part of COPS, a transect of five supersites, with synergic remote sensing instruments, was set up from the Vosges mountains to the lee side of the Black Forest close to Stuttgart, crossing the Rhine Valley, the Hornisgrinde Mountain and the Murg Valley. Figure 1 illustrates the locations of the different supersites: Vosges Mountains (V), Rhine Valley (R), Hornisgrinde Mountain (H), Murg Valley (M) and Stuttgart (S). The distance between supersites $V$ and $\mathrm{R}$ is approximately $50 \mathrm{~km}$ along the southwest-northeast direction, the distance between supersites $\mathrm{R}$ and $\mathrm{H}$ is $10.5 \mathrm{~km}$ along the northwest-southeast direction, the distance between supersites $\mathrm{H}$ and $\mathrm{M}$ is $\sim 15 \mathrm{~km}$, again along the northwest-southeast direction, while the distance between supersites $\mathrm{M}$ and $\mathrm{S}$ is $\sim 30 \mathrm{~km}$ along the southwest-northeast direction.

All supersites were equipped with soil moisture sensors, turbulence or energy balance stations, radars (cloud, precipitation and/or wind), radiosonde launching facilities, Global Positioning System (GPS) stations, microwave radiometers and surface meteorology instrumentation; all supersites except Stuttgart were also equipped with water vapour lidars. A total of six lidar systems were operated (two airborne and four ground-based) within COPS. Besides the water vapour lidars, four Doppler wind and three temperature lidar systems were also present. Four out of these 13 systems were additionally equipped with Raman channels for the characterization of aerosol optical properties.

The water vapour measurements considered in this study were performed during dedicated flights of the two airborne lidars over the four supersites equipped with ground-based water vapour lidars. These flights took place primarily throughout the month of July with the Deutsches Zentrum für Luft- und Raumfahrt (DLR) DIAL, hereafter referred to as DLR DIAL, operating in the time frame 6 July-1 August 2007 and the LEANDRE II of the Centre National de la Recherche Scientifique (CNRS), hereafter referred to as CNRS DIAL, operating in the period 10 July-2 August 2007.

\section{Lidar Systems}

\subsection{General remarks}

Six water vapour lidar systems participated in COPS. Two of them, based on the differential absorption lidar (DIAL) technique (e.g. Bösenberg, 1998), were operated on airborne platforms: the DLR DIAL and the CNRS DIAL. Additionally, four water vapour lidar systems were operated on the ground, three of them using the Raman lidar technique: the University of BASILicata Raman lidar system (BASIL), located in the supersite $\mathrm{R}$, the Institut Géographique National (IGN) Raman lidar, located in supersite V, and BERTHA of the Leibniz Institute for Tropospheric Research (IfT), hereon referred to as BERTHA Raman lidar, located in supersite M. A fourth lidar system on the ground, based on the DIAL technique, was operated by the Institute of Physics and Meteorology (IPM) of the University of Hohenheim (UHOH DIAL) and was located at supersite $\mathrm{H}$.

The Raman lidar technique for the determination of the water vapour mixing ratio profile has been extensively discussed in the literature (for a recent review, see Whiteman, 2003). The water vapour mixing ratio can be obtained from the power ratio of water vapour to molecular nitrogen vibrational Raman signals. This ratio needs to be calibrated through an independent measurement, which is usually provided by radiosonde, GPS or microwave radiometer measurements. Raman lidar is a very powerful and straightforward technique to measure water vapour mixing ratio profiles, especially at night, but performances are somewhat degraded during the daytime because of the small Raman cross-sections, reducing the covered vertical range to $5 \mathrm{~km}$ (Althausen et al., 2000; Whiteman et al., 2006; Di Girolamo et al., 2009a).

The DIAL technique makes use of laser probing of the atmosphere at two wavelengths; the on-line wavelength is centred on a water vapour absorption line and the off-line wavelength is positioned outside of the absorption line to act as a reference for the scattering and extinction properties of the atmosphere (e.g. Werner and Herrmann, 1981; Cahen et al., 1982; Bösenberg, 1998; Wulfmeyer and Bösenberg, 1998). The selection of the on-line and off-line wavelength pairs was performed before COPS for all involved DIAL systems on the basis of climatological information on the water vapour distribution and variability for the COPS area. The water vapour number density is determined from the derivative of the logarithm of the ratio of the backscattered on- and off-line signals. As the water vapour absorption coefficient for the on-line and off-line radiation is known from high-accuracy laboratory measurements, two alternating atmospheric backscatter signals measured at the on-line and off-line wavelengths allow the determination of the water-vapour number density profile, while instrumental parameters cancel out. Consequently, a calibration of DIAL data is not required.

In this paper, comparisons between DIAL systems have been performed in terms of water vapour number concentration (water vapour molecules per $\mathrm{m}^{3}$ ), and comparisons between DIAL and Raman lidars are carried out in terms of water vapour mixing ratio. The water vapour mixing ratio, $x_{\mathrm{H} 2 \mathrm{O}}\left(\mathrm{kg} \mathrm{kg}^{-1}\right)$, is calculated from the water vapour number concentration, $n_{\mathrm{H} 2 \mathrm{O}}$ (molecules per $\mathrm{m}^{3}$ ), with the following expression (Warnecke, 1997):

$$
x_{\mathrm{H}_{2} \mathrm{O}}=\left(\frac{p}{m_{\mathrm{H}_{2} \mathrm{O}} n_{\mathrm{H}_{2} \mathrm{O}} R T}-1.6078\right)^{-1}
$$

where $m_{\mathrm{H} 2 \mathrm{O}}$ is the water molecular mass $(18.01508), R$ is the gas constant of dry air $\left(0.28704 \mathrm{~J} \mathrm{~g}^{-1} \mathrm{~K}^{-1}\right), p$ is pressure and $T$ is temperature. DLR DIAL and CNRS DIAL measurements 
of water vapour number concentration are converted into mixing ratio measurements with Eq. (1) using pressure and temperature information obtained from a reference atmospheric model (midlatitude summer). Unfortunately dropsondes could not be used in the COPS area for airsafety reasons. Deviations between real temperature and pressure profiles and model profiles have been verified to yield a bias on $x_{\mathrm{H} 2 \mathrm{O}}$ smaller than $1 \%$. Effects associated with the variability of temperature and pressure within a distance of $10 \mathrm{~km}$ in this mountain region are found to be even smaller.

\subsection{DLR DIAL}

During COPS, a novel combination of wind and water vapour lidars was operated by DLR. From the combination of both a water vapour DIAL and a Doppler wind lidar on the Falcon, aircraft measurements of the humidity variability and its transport throughout the troposphere and measurements of latent heat flux profiles in the boundary layer can be obtained (Kiemle et al., 2011). For the DIAL instrument, a new multi-wavelength system called WALES was deployed for the first time (for a detailed system description, see Wirth et al. (2009)). During COPS only three out of four possible wavelengths could be used for water vapour measurements and the online diagnostics to assess the spectral properties of the laser system were not fully implemented. So the bias estimates determined in this paper are valid only for the COPS measurements but may be not representative for the fully operational system used in later campaigns.

DLR DIAL data were processed with a vertical resolution of $280 \mathrm{~m}$ in order to obtain water vapour profiles with a maximum statistical uncertainty of $5 \%$. Additionally, in order to further reduce signal statistical fluctuations, we considered an integration time of $50 \mathrm{~s}$, corresponding to a horizontal integration length of $\sim 10 \mathrm{~km}$. However, for the intercomparison with the UHOH DIAL, which can provide water vapour profiles with a time resolution of $10 \mathrm{~s}$ during daytime and was located on a mountain peak with steep orography in the vicinity, a DLR DIAL integration time of $4 \mathrm{~s}$ was used to minimize the sampling errors in complex terrain.

\subsection{CNRS DIAL}

During COPS, the CNRS DIAL operated in nadir-pointing mode from the Falcon 20 of SAFIRE. The details concerning the design of the CNRS DIAL system and the standard DIAL signal processing are given in Bruneau et al. (2001a, 2001b) and are only briefly presented here. The system includes a tunable laser whose emission is positioned precisely upon an absorption line selected from two rotation-vibration bands in the near infrared $(727-770 \mathrm{~nm})$. As discussed in Bruneau et al. (2001a), CNRS DIAL characteristics permit water vapour mixing ratio measurements to be made with a precision ranging from less than $0.1 \mathrm{~g} \mathrm{~kg}^{-1}$ at $4.5 \mathrm{~km}$ above sea level (a.s.l.) to less than $0.4 \mathrm{~g} \mathrm{~kg}^{-1}$ near the surface (on average) for an along-beam resolution of $300 \mathrm{~m}$ and accumulation of 200 individual profiles (corresponding to an along-track resolution of nearly $3 \mathrm{~km}$ ). Systematic errors associated with the CNRS DIAL system are described in Bruneau et al. (2001b).
Within COPS, the CNRS DIAL data acquired during the 14 Falcon-20 flights were obtained using mainly two weak water vapour absorption bands, centred at 730.4 and $731.2 \mathrm{~nm}$, optimal for water vapour retrievals in atmospheres characterized by moderate integrated water vapour contents (i.e. between 18 and $28 \mathrm{~kg} \mathrm{~m}^{-2}$ ).

In order to reduce signal statistical fluctuations, we considered an integration time of $80 \mathrm{~s}$ for night-time measurements, corresponding to a horizontal integration length of $\sim 10 \mathrm{~km}$. For daytime comparisons, an integration time of $80-240 \mathrm{~s}$ was considered, corresponding to a horizontal integration length of $10-30 \mathrm{~km}$. Different integration times are considered in order to deal with profiles characterized by comparable signal-to-noise ratio (SNR) levels and random errors. In fact, profiles collected at different times of the day are characterized by different levels of background light associated with variable solar irradiance. Thus, longer integration times (up to $240 \mathrm{~s}$ ) are considered for those profiles collected in the central portion of the day, while shorter times are considered for morning or evening profiles (a value of $80 \mathrm{~s}$ being selected for profiles in the proximity of dawn/dusk). The vertical resolution of the measurements is $250 \mathrm{~m}$, but data are provided with a vertical step of $15 \mathrm{~m}$.

\subsection{BASIL}

BASIL operated between 25 May and 30 August 2007 and collected more than 500 hours of measurements during 58 measurement days and 34 intensive observation periods (IOPs). The major feature of the system is represented by its capability to perform high-resolution and accurate measurements of atmospheric temperature and water vapour, both during daytime and night-time, based on the application of the rotational and vibrational Raman lidar techniques in the ultraviolet (Di Girolamo et al., 2004, 2006, 2009a, 2009b). Specifically, the water vapour profiles are determined from the Raman backscatter signals at 387 and $407 \mathrm{~nm}$ from nitrogen and water vapour molecules, respectively (Melfi et al., 1969; Cooney, 1971; Melfi, 1972). Besides temperature and water vapour, BASIL is capable of providing measurements of particle backscatter at 355, 532 and $1064 \mathrm{~nm}$, particle extinction at 355 and $532 \mathrm{~nm}$ and particle depolarization at 355 and $532 \mathrm{~nm}$ (Griaznov et al., 2007; Mona et al., 2007; Bhawar et al., 2008; Di Girolamo et al., 2009a). For the purpose of determining particle size and microphysical parameters, measurements of the particle backscattering coefficient at 355, 532 and $1064 \mathrm{~nm}$, of the particle extinction coefficient at 355 and $532 \mathrm{~nm}$ and of the depolarization ratio at $355 \mathrm{~nm}$ are used (Di Girolamo et al., 2009c). The calibration procedure used for BASIL has been described in Di Girolamo et al. (2009a). Specifically, during COPS the calibration was performed based on an extensive comparison of the water vapour mixing ratio data from lidar and simultaneous radiosondes (Vaisala RS92 were considered for this purpose). Figure 2 illustrates water vapour measurements from BASIL on 1 August 2007, expressed in terms of integrated water vapour, as compared with simultaneous GPS and radiosonde measurements of this same parameter.

In order to reduce signal statistical fluctuations, we considered an integration time of $1 \mathrm{~min}$ for night-time measurements and of $5 \mathrm{~min}$ for daytime measurements. The vertical resolution is $150 \mathrm{~m}$, but data are provided with 


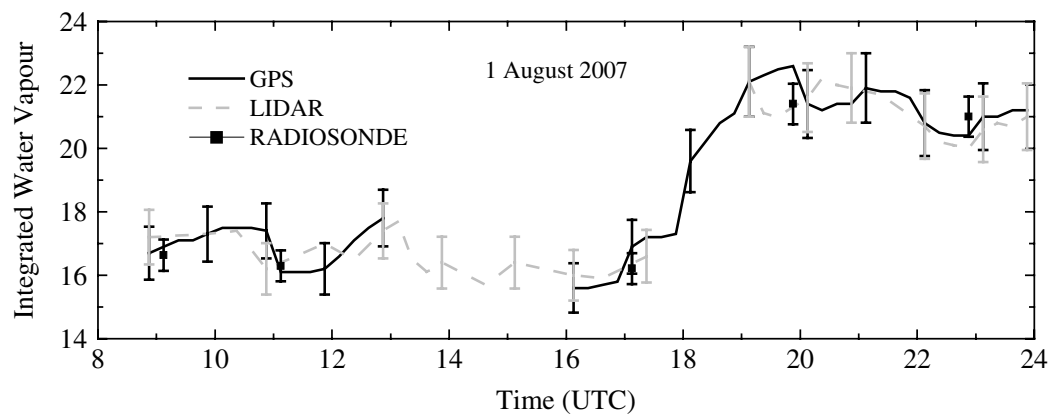

Figure 2. Water vapour measurements from BASIL, expressed in terms of integrated water vapour, as compared with simultaneous GPS and radiosonde measurements of this same parameter.

a vertical step of $30 \mathrm{~m}$. Based on an integration time of $5 \mathrm{~min}$ and a vertical resolution of $150 \mathrm{~m}$, the random error affecting water vapour mixing ratio measurements is usually smaller than $10 \%$ for daytime operation and smaller than $2 \%$ for night-time operation up to $4 \mathrm{~km}$. The vertical range (considered as the range where random error is smaller than $100 \%$ ) is $5 \mathrm{~km}$ for daytime measurements and $12-14 \mathrm{~km}$ for night-time measurements. The statistical uncertainty affecting BASIL measurements was estimated through the application of Poisson statistics, which are well suited for data acquired in photon-counting mode (Di Girolamo et al., 2009a).

\subsection{UHOH DIAL}

A new ground-based scanning water-vapour DIAL was deployed for the first time during COPS at supersite $\mathrm{H}$ in the northern Black Forest (Behrendt et al., 2009). The instrument is affiliated with the University of Hohenheim (UHOH). For brevity, we refer to this system as $\mathrm{UHOH}$ DIAL in the following.

The UHOH DIAL measures profiles of atmospheric water vapour number density and particle backscatter during both day and night. To our best knowledge, this DIAL currently provides the highest resolution remote sensing data of tropospheric water vapour worldwide, i.e. up to resolutions of $1 \mathrm{~s}$ and $30 \mathrm{~m}$. This is achieved with the combination of four novel components based on the methodology introduced in Wulfmeyer and Bösenberg (1996): a highpower Ti:Sapphire laser transmitter $(>4 \mathrm{~W}$ average power, with a repetition rate of $250 \mathrm{~Hz}$ ) emitting laser radiation in the near infrared between 815 and $820 \mathrm{~nm}$ (Wagner et al., 2010), a combination of a small near-field and a large far-field telescope, efficient detectors, and a high-speed data acquisition system. The whole system is mounted on a mobile laboratory (a $12 \mathrm{~m}$ trailer). While the system has scanning capability, only vertical measurements were included in this paper.

The water vapour number density data presented here have not yet been corrected for the Rayleigh-Doppler effect, i.e. an artificial oscillation in height might appear at large aerosol gradients and cloud edges. We estimate that the bias affecting absolute humidity data is $<5 \%$ in regions without large gradients of backscatter ratio while precision (statistical uncertainty) for cloud-free measurements is smaller than $10 \%$ or $0.1 \mathrm{~g} \mathrm{~kg}^{-1}$, whichever is larger (see Wulfmeyer and Walther, (2001a, 2001b) for details on the expected water vapour DIAL precision). In order to reduce sampling errors in the intercomparisons, we applied a temporal averaging of 5 min to the UHOH DIAL data in this study.

\subsection{BERTHA Raman lidar}

The Institute for Tropospheric Research contributed to COPS with the deployment of a wind lidar and of the multi-wavelength Raman lidar BERTHA at supersite M. BERTHA simultaneously emits six laser pulses at 355, 400, 532, 710, 800 and $1064 \mathrm{~nm}$ and measures the elastically and inelastically backscattered light for the determination of aerosol optical parameters, water vapour, and temperature profiles (Althausen et al., 2000; Tesche et al., 2009).

Differential scattering due to the wavelength dependence of the Rayleigh scattering has been taken into account. The differential scattering due to particle scattering was neglected since this effect is smaller than the relative statistical error affecting water vapour mixing ratio measurements (Herold, 2009). An interference filter with a full width at half maximum of $0.25 \mathrm{~nm}$ and a maximum transmission at $407.475 \mathrm{~nm}$ was used in the water vapour channel. As atmospheric temperature varies with height, Raman backscatter spectra from atmospheric molecules vary with height and the transmission of the receiving optics must be taken into account (Whiteman, 2003). The calibration of the system was done by comparing BERTHA data with radiosonde profiles (Vaisala RS92). Error sources are associated with the signal noise, with the correction for Rayleigh scattering and for the temperature dependency of the filters' transmission, as well as with the determination of the calibration constant. The error associated with filter transmission was neglected since this is small with respect to the signal statistical error and the error associated with the determination of the calibration constant.

During COPS, water vapour and temperature measurements were limited to night-time. In order to reduce signal statistical fluctuations, we used an integration time of $3 \mathrm{~min}$; the vertical resolution is $150 \mathrm{~m}$, but data are provided with a vertical step of $60 \mathrm{~m}$.

\subsection{IGN Raman lidar}

The Rameau lidar, hereafter referred to as IGN Raman lidar, has been developed by the Institut Géographique National (IGN) in cooperation with the Laboratoire Atmosphères, Milieux, Observations Spatiales (CNRS-UPMC). The system is intended to be operated in combination with GPS receivers to improve troposphere modelling in precise GPS analysis (Bosser et al., 2010). The IGN Raman lidar was operational 
during COPS at supersite V during the entire month of July 2007, for a total of about $200 \mathrm{~h}$ covering 25 measurement sessions. While the system was originally intended to operate both at night and in daytime, technical problems prevented it from performing precise daytime water vapour measurements, and observations were therefore limited to night-time and night-to-day and day-to-night transitional periods.

The system, enclosed in a van, uses a tripled Nd:YAG laser $(355 \mathrm{~nm})$, with an average power of about $0.8 \mathrm{~W}$. The elastic (355 nm) and Raman components (387 nm for molecular nitrogen and $408 \mathrm{~nm}$ for water vapour) are spectrally isolated with narrow-band $(0.4 \mathrm{~nm})$ interference filters. The transmission terms in the Raman equation are corrected with the aid of a standard atmospheric model (again midlatitude summer), while the temperature dependence of the Raman cross-section convolved with the interference filter band pass is currently neglected.

Humidity profiles are provided with a vertical resolution between $15 \mathrm{~m}$ and $300 \mathrm{~m}$. Based on an integration time of $5 \mathrm{~min}$, typical vertical range (with random error smaller than $100 \%$ ) for night-time measurements is $6-7 \mathrm{~km}$. During daytime, measurement precision is severely reduced due to the high levels of solar irradiance: the vertical range is $1-3 \mathrm{~km}$ in the day-to-night transition period and drops to a few hundred metres in the middle of the day for a temporal resolution of $10 \mathrm{~min}$ or higher. The spatial and temporal integration grids with varying resolution as a function of altitude enable the improvement of the signal-to-noise ratio, especially in upper layers where backscattered signals are usually weak. Bias in water vapour mixing ratio estimates at low signal photo-counting rates due to fluctuations in the nitrogen signal in the denominator of the ratio are corrected using the methodology presented in Bosser et al. (2007). Finally, water vapour mixing ratio profiles are calibrated using night-time collocated radiosondes launched at supersite $\mathrm{V}$ in the range $1-3 \mathrm{~km}$ (10 calibration sessions). For the present intercomparison study, we used an integration time of $15 \mathrm{~min}$. Here, primarily because of the smaller average laser power, a longer integration time is required compared to BASIL and BERTHA in order to achieve comparable SNR levels.

\section{Intercomparison Strategy}

The DLR DIAL was flying at a speed of $180-200 \mathrm{~m} / \mathrm{s}$, while the CNRS DIAL had a flying speed of $110-120 \mathrm{~m} / \mathrm{s}$. For all flights performed during COPS, we determined the distances between the ground tracks of the two airborne lidars and the ground-based systems.

During IHOP_2002, Behrendt et al. (2007a,b) used a cut-off distance of $20 \mathrm{~km}$ in the flat terrain for identifying possible intercomparison cases between ground-based and airborne water vapour lidars. This distance was considered to be a reasonable maximum limit, because the natural heterogeneity of the water vapour field in the lower troposphere was generally found to be too large to draw conclusions on instrumental performances at larger distances.

It has to be pointed out that the possibility to compare measurements from different sensors is generally dependent on meteorological conditions. The wind speed and the horizontal variability of the water vapour field, as well as the orientation of the aircraft with respect to the mean

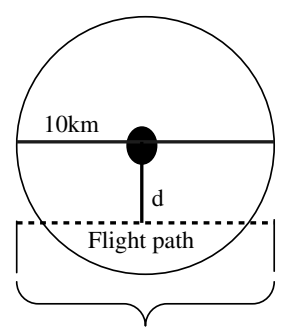

integration time $=50 \mathrm{sec}$ for DLR DIAL and $80 \mathrm{sec}$ for CNRS DIAL hor. integration length $\sim 10 \mathrm{~km}$ for both DLR DIAL and CNRS DIAL

Figure 3. Approach used to identify the airborne lidar profiles to be compared with the ground-based lidar profiles. The dot indicates the site where the ground-based lidar is located, the circle identifies the $10 \mathrm{~km}$ distance from the site, the dotted line indicates the flight path and ' $\mathrm{d}$ ' represents the minimum distance between the site and the flight path.

wind direction, must be considered. IHOP_2002 took place during summer 2002 in the Southern Great Plains of the United States. This area is mostly flat, while the COPS area is mountainous, with a highly variable orography, resulting in a larger horizontal variability of the humidity field for COPS than for IHOP_2002. Additionally, most of the measurements considered here were carried out during the month of July, which was frequently characterized by frontal activity and consequently by a large meteorologically driven variability of the humidity field.

For the above reasons, we selected a cut-off distance of $10 \mathrm{~km}$ between the footprint of the airborne DIALs and ground-based stations. This is also found to be a good compromise in terms of statistical sample size since the resulting numbers of possible COPS comparisons is still large enough to allow a reliable and accurate statistical analysis. The $10 \mathrm{~km}$ distance corresponds to a flight time of the order of $1 \mathrm{~min}$ for both the DLR Falcon and the SAFIRE Falcon, which we can assume as a maximum time lag for which water vapour homogeneity in the lower troposphere is present and we can draw conclusions on instrumental performances. Water vapour homogeneity over a distance of $10 \mathrm{~km}$ was also verified by comparing data from radiosondes simultaneously launched from supersites $\mathrm{R}$ and $\mathrm{H}$, which are located $10.5 \mathrm{~km}$ apart, the former in the Rhine Valley and the latter on the Hornisgrinde mountain peak.

Figure 3 illustrates the approach we applied to identify the airborne lidar profiles to be considered for comparison with the ground-based lidar profiles. The dot identifies the site where the vertical-pointing ground-based lidar is located, while the circle identifies the $10 \mathrm{~km}$ distance from the site. For the intercomparisons with the ground-based Raman lidar systems, the airborne data were averaged over a time period of $50 \mathrm{~s}$ for the DLR DIAL and of $80 \mathrm{~s}$ for the CNRS DIAL, corresponding to a horizontal integration length for both systems of $\sim 10 \mathrm{~km}$. The centre time is coincident with the time when the aircraft reaches its minimum distance from the ground site.

Intercomparison tables were created for all days when the airborne DIALs were flying. These are available on request for all other IOPs of COPS.

After setting up intercomparison tables for all IOPs and special observation periods (SOPs), we checked the operational status of the different sensors, their operation modes and the availability of good quality data, and, keeping in mind the $10 \mathrm{~km}$ cut-off criterion, we came out with a list of possible lidar-to-lidar intercomparisons (Table I). 
Table I. Possible lidar-to-lidar intercomparison profiles for water vapour during COPS.

\section{BASIL Raman Lidar (Site R) vs CNRS DIAL \\ BASIL Raman Lidar (Site R) vs DLR DIAL}

\section{UHOH DIAL (Site H) vs CNRS DIAL \\ UHOH DIAL (Site H) vs DLR DIAL}

Bertha IFT (Site M) vs CNRS DIAL

Bertha IFT (Site M) vs DLR DIAL

IGN Raman Lidar (Site V) vs CNRS DIAL

IGN Raman Lidar (Site V) vs DLR DIAL
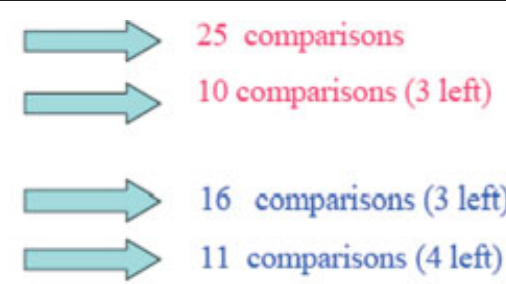

16 comparisons (3 left)

11 comparisons (4 left)

6 comparisons

9 comparisons (none left)

9 comparisons

1 comparisons (none left)

\section{CNRS DIAL vs DLR DIAL}

14 comparisons (5 left)

The table lists the number of possible comparisons between all ground-based lidars and the two airborne DIALs and, in parenthesis, the number of those left after quality control and operation mode check. The last line shows the possible airborne-to-airborne intercomparison profiles. This table is available in colour online at wileyonlinelibrary.com/journal/qj.

The present intercomparison effort benefited from dedicated flights performed by the CNRS DIAL on 16 July, 25 July and 31 July in the frame of the European Facility for Airborne Research (EUFAR) Project H2OLidar, which was funded by the European Commission under the $7^{\text {th }}$ Framework Programme. Each flight had a duration of 3 hours for a total of 9 hours. The primary goal of the H2OLidar Project was the intercomparison of airborne and ground-based lidar measurements of atmospheric water vapour, with a particular focus on the measurements performed by CNRS DIAL and BASIL. Most of the intercomparisons illustrated in this paper ( 31 out of 50) are based on lidar data collected during these EUFAR flights. To fulfil the goals of H2OLidar, measurements were needed in clear sky conditions or in the presence of high clouds (i.e. clouds located above the flying altitude of the involved airborne DIALs). These goals were met for the flights on 16 July, 25 July and 31 July.

\section{Algorithms Used}

In order to carry out an accurate error analysis for the lidar systems involved in the intercomparison effort, simultaneous and co-located data from the different lidar pairs are used to compute mutual bias and RMS deviations as a function of altitude. To compute these parameters, we utilized the expressions used by Behrendt et al. (2007a,b):

$$
\begin{aligned}
\operatorname{BIAS}_{i, \text { relative }}\left(z_{1}, z_{2}\right) & =\frac{2 \sum_{z=z_{1}}^{z_{2}}\left\{q_{1}(z)-q_{2}(z)\right\}}{\sum_{z=z_{1}}^{z_{2}}\left\{q_{1}(z)+q_{2}(z)\right\}} \\
\operatorname{RMS}_{i, \text { relative }}\left(z_{1}, z_{2}\right) & =\frac{2 \sqrt{N_{z} \sum_{z=z_{1}}^{z_{2}}\left\{q_{1}(z)-q_{2}(z)\right\}^{2}}}{\sum_{z=z_{1}}^{z_{2}}\left\{q_{1}(z)+q_{2}(z)\right\}}
\end{aligned}
$$

where $i$ is an index denoting the intercomparison sample, $q_{1}(z)$ and $q_{2}(z)$ are the water vapour mixing ratio values (for Raman lidar to DIAL comparison) or the water vapour number concentration values (for DIAL to DIAL comparison) measured by the two lidars under evaluation at height $z, z_{1}$ and $z_{2}$ are the lower and upper boundary of the height interval considered, respectively, and $N_{z}$ is the total number of data points for each sensor in the interval $\left[z_{1}, z_{2}\right]$.

The absolute bias and root-mean-square deviations are obtained from these expressions through the multiplication by the mean of the data of the two instruments:

$$
2 \sum_{z=z_{1}}^{z_{2}}\left\{q_{1}(z)+q_{2}(z)\right\} / N_{z} .
$$

In the above expressions the mean of the measurement result of the two instruments is used as reference rather than the measurement result of one of the two instruments. This procedure results in more objective values than considering one of the sensors as reference (Behrendt et al. (2007a,b).

The estimate of the relative bias and root-meansquare deviations allows us to quantify the mutual performance of the two compared instruments, i.e. the performance of one instrument with respect to the other. The bias identifies an offset between the two sensors which may be caused by different sources of systematic error affecting the two measurements, primarily depending on the procedure and/or instruments used to calibrate them. The bias quantifies the relative accuracy of the compared instruments. The bias affecting water vapour lidar measurements is frequently characterized by a height-dependent behaviour, for example associated with spectroscopic effects (e.g. the temperature/pressuredependent effects of the water vapour Raman backscatter and absorption cross-sections) or with the different instrumental characteristics of the compared sensors (e.g. different overlap functions or a slightly nonlinear behaviour of the acquisition systems). In contrast, the root-mean-square deviation includes all possible differences between the measurement results of the two compared instruments. Thus it includes differences associated with the systematic and statistical uncertainties affecting the two instruments 
and the natural differences in the water vapour content of the air masses sounded by the two sensors (not completely negligible even when considering a cut-off distance of $10 \mathrm{~km}$ between the compared instruments). The root-mean-square deviation provides an upper limit for the sum of the statistical uncertainties affecting the two instruments.

As in Behrendt et al. (2007a,b), in the present analysis we selected a vertical window width $\left[z_{1}, z_{2}\right]$ of $500 \mathrm{~m}$. This window is large enough when compared to the vertical resolution of the different water vapour lidars to allow the inclusion of independent measurements, but still small enough to allow the investigation of the vertical variability of bias and RMS deviations. In the following analysis, we are considering a bottom window with $z_{1}=500 \mathrm{~m}$ above station level. As all heights in this paper are expressed above sea level, height $z_{1}$ for the bottom window, $z_{\text {bott }}$, is taken to be 500,1000 or $1500 \mathrm{~m}$ for the different intercomparisons carried out at the different supersites as a result of the different elevations of these supersites. We evaluate bias and RMS deviations in the six vertical windows up to $3500 \mathrm{~m}$ above station level (i.e. $z_{2}$ for the top window, $z_{\text {top }}$, becoming 3500,4000 or $4500 \mathrm{~m}$ for the different intercomparisons carried out at the different supersites). In the case of intercomparisons involving only airborne DIAL systems, we extended the comparison to higher levels, considering seven vertical windows up to $z_{\text {top }}=4000 \mathrm{~m}$ as a result of the better daytime performances of these systems when compared to Raman lidars. An extended vertical interval up to $z_{\text {top }}=4500 \mathrm{~m}$ was also considered in the case of intercomparisons involving only night-time Raman lidar measurements because of the better performances (smaller random errors) of Raman lidars at night. Profiles of mean bias and RMS deviations have been finally computed considering the total number of possible intercomparison cases for each pair of sensors.

As bias and RMS show a height variability, we finally estimated an overall vertically-averaged mean bias and RMS deviations over the whole intercomparison analysis range, which is obtained through the application of the weighted mean:

$$
\bar{x}\left(z_{\mathrm{bott}}, z_{\mathrm{top}}\right)=\frac{\sum_{i=1}^{N} w_{i} x_{i}}{\sum_{i=1}^{N} w_{i}}
$$

where $x_{i}$ denoted the relative/absolute bias or RMS value in the $i$ th vertical interval, $w_{i}$ is the corresponding weight and $N$ is the number of vertical windows. The summation is extended over six or seven vertical windows (i.e. $N=6$ or 7 ), depending on the considered instrument pair. $w_{i}$ is given by the number of intercomparisons possible in the $i$ th vertical window and varies between zero and the total number of intercomparisons between the two compared instruments. The consideration of a weighted mean is required because, in the case of missing data at some specific heights (i.e. in specific vertical windows), the number of intercomparisons may be smaller and thus data from these heights must have a lower weight in the overall mean.

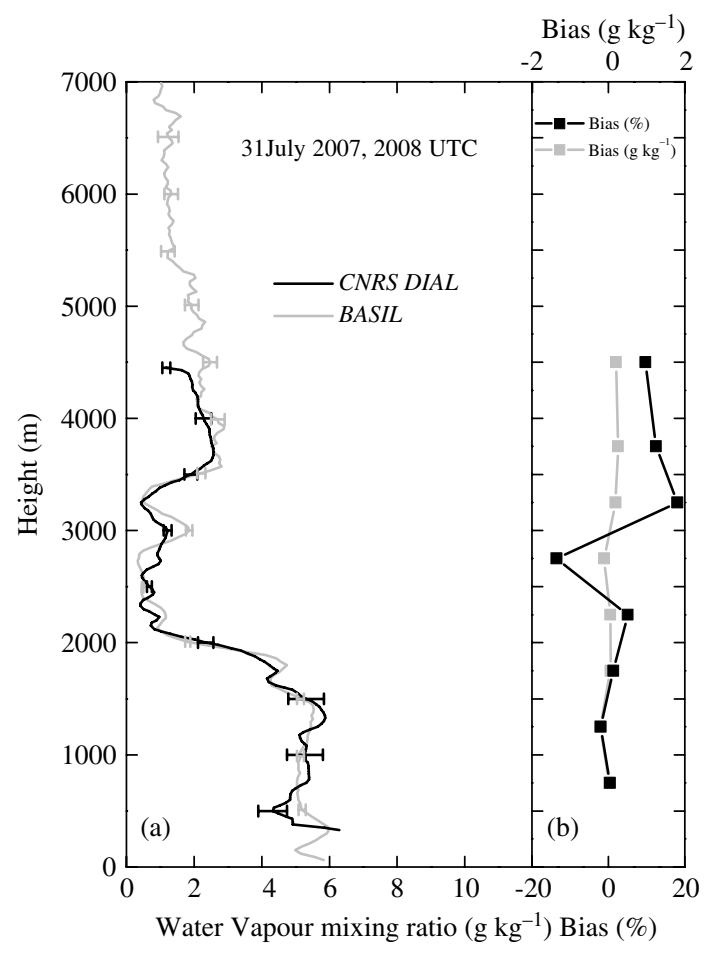

Figure 4. (a) Comparison between BASIL and CNRS DIAL at 2008 UTC on 31 July 2007, and (b) deviations, both absolute and relative, between the two sensors.

\section{Results}

In this section, we illustrate and discuss the intercomparison results for all the different lidar pairs, including the airborneto-ground-based intercomparisons (BASIL vs. CNRS DIAL, BASIL vs. DLR DIAL, UHOH DIAL vs. CNRS DIAL, UHOH DIAL vs. DLR DIAL, BERTHA vs. CNRS DIAL, IGN Raman lidar vs. CNRS DIAL) and the airborne-to-airborne intercomparisons (CNRS DIAL vs. DLR DIAL).

\subsection{BASIL vs. airborne DIALs}

\subsubsection{BASIL vs. CNRS DIAL}

The list of the possible intercomparisons between BASIL and the CNRS DIAL is given in Table II. The intercomparisons include all overpasses within a maximum distance of $10 \mathrm{~km}$ between the footprint of the CNRS DIAL and BASIL after data quality control and operation mode check. A total of 25 profile-to-profile intercomparisons are listed which can be divided into two subgroups: there are 18 intercomparisons with a minimum distance not exceeding $5 \mathrm{~km}$ and 7 intercomparisons with a minimum distance between 5 and $10 \mathrm{~km}$.

Figure 4 shows an example of a comparison between BASIL and CNRS DIAL at 2008 UTC on 31 July 2007 with a minimum distance between the two sensors of $1.8 \mathrm{~km}$. The right portion of Figure 4 shows the deviations, both absolute $\left(\mathrm{g} \mathrm{kg}^{-1}\right)$ and relative (\%), between the two sensors. To compute deviations, CNRS DIAL data have been interpolated to BASIL data heights. The two profiles show a very good agreement with deviations not exceeding $0.25 \mathrm{~g} \mathrm{~kg}^{-1}$ or $20 \%$. Table II also lists the mean bias and RMS deviation over the vertical interval $0.5-3.5 \mathrm{~km}$ for all comparison cases. None of the mean bias values exceeds $\pm 30 \%$ while mean RMS values do not exceed $75 \%$. The table also reports 
Table II. Intercomparisons between BASIL and the CNRS DIAL using a cut-off distance of $10 \mathrm{~km}$.

\begin{tabular}{|c|c|c|c|c|c|c|}
\hline No. & Date & Time UTC) & Min. distance $(\mathrm{km})$ & BIAS (\%) & RMS dev. (\%) & Aircraft track vs. valley \\
\hline 1 & 14 July 2007 & 1118 & 5.43 & -4.79 & 22.06 & cross \\
\hline 2 & 15 July 2007 & 0630 & 9.70 & 0.89 & 22.75 & cross \\
\hline 3 & 16 July 2007 & 0609 & 2.24 & 1.42 & 20.86 & cross \\
\hline 4 & 16 July 2007 & 0624 & 2.15 & -7.21 & 32.78 & cross \\
\hline 5 & 16 July 2007 & 0638 & 2.03 & -4.47 & 28.50 & cross \\
\hline 6 & 16 July 2007 & 0653 & 1.066 & -4.18 & 24.83 & cross \\
\hline 7 & 16 July 2007 & 0707 & 2.40 & 16.16 & 25.08 & cross \\
\hline 8 & 16 July 2007 & 0728 & 7.51 & -30.24 & 43.90 & cross \\
\hline 9 & 19 July 2007 & 1304 & 3.19 & -3.36 & 30.02 & cross \\
\hline 10 & 25 July 2007 & $\underline{1902}$ & $\underline{7.12}$ & $-\underline{1.09}$ & $\underline{50.79}$ & $\underline{\text { cross }}$ \\
\hline 11 & $\overline{25 \text { July } 2007}$ & $\underline{1924}$ & $\underline{2.21}$ & $\underline{1.75}$ & $\underline{28.12}$ & cross \\
\hline 12 & $\overline{25 \text { July } 2007}$ & $\overline{1937}$ & $\underline{1.30}$ & $\underline{\underline{0.21}}$ & $\underline{29.39}$ & cross \\
\hline 13 & 25 July 2007 & $\overline{2004}$ & $\overline{2.66}$ & $\overline{-6.06}$ & $\overline{38.03}$ & $\overline{\text { cross }}$ \\
\hline 14 & $\overline{25 \text { July } 2007}$ & $\underline{2016}$ & $\underline{2.706}$ & -3.18 & $\overline{73.74}$ & cross \\
\hline 15 & 25 July 2007 & 2036 & 4.43 & $-\underline{3.29}$ & $\underline{37.82}$ & cross \\
\hline 16 & 30 July 2007 & 0934 & 9.5 & 9.26 & 29.10 & cross \\
\hline 17 & 31 July 2007 & $\underline{1926}$ & $\underline{2.011}$ & 1.91 & $\underline{36.10}$ & cross \\
\hline 18 & 31 July 2007 & 1940 & 1.61 & $\underline{5.67}$ & 21.04 & cross \\
\hline 19 & 31 July 2007 & $\underline{1954}$ & 1.64 & $\underline{11.21}$ & $\underline{31.29}$ & cross \\
\hline 20 & $\overline{31 \text { July } 2007}$ & $\overline{2008}$ & $\overline{1.842}$ & $\overline{1.53}$ & $\overline{23.58}$ & $\overline{\text { cross }}$ \\
\hline 21 & 31 July 2007 & $\overline{2021}$ & $\overline{3.01}$ & $\overline{-9.26}$ & $\overline{31.37}$ & $\overline{\text { cross }}$ \\
\hline 22 & $\overline{31 \text { July } 2007}$ & $\overline{2042}$ & $\overline{3.017}$ & $-\overline{1.93}$ & $\overline{31.74}$ & $\overline{\text { cross }}$ \\
\hline 23 & $\overline{1 \text { August } 2007}$ & $\overline{0808}$ & $\overline{1.62}$ & $-\overline{16.26}$ & $\overline{36.97}$ & $\overline{\text { cross }}$ \\
\hline 24 & 1 August 2007 & 1032 & 8.8 & 0.90 & 21.14 & parallel \\
\hline \multirow[t]{2}{*}{25} & 1 August 2007 & 1344 & 5.22 & -5.46 & 24.36 & cross \\
\hline & & Overall & & $-2.13 \pm 32.89$ & $32.89 \pm 1.21$ & \\
\hline
\end{tabular}

The given time corresponds to the minimum distance between the two sensors. The mean bias and RMS deviation have been determined over the vertical interval $0.5-3.5 \mathrm{~km}$ a.s.l. Night-time intercomparisons have been underlined (local noon is at about $1130 \mathrm{UTC}$ ).

whether the aircraft track is parallel or perpendicular to the Rhine Valley. All overpasses in Table II are perpendicular to the valley, except for 1 August 2007, 1032 UTC, which is parallel to the valley. The mean bias value for this comparison is very small $(0.90 \%)$, as a result of the smaller heterogeneity of the water vapour field along the valley than in the direction perpendicular to the valley, where mountains and a highly variable orography are present.

For all intercomparisons, bias and RMS deviation between the two sensors have been computed in the $500 \mathrm{~m}$ height intervals from 0.5 to $3.5 \mathrm{~km}$ a.s.l. (Figure 5). With the exception of a few points, most bias values are within $\pm 2 \mathrm{~g} \mathrm{~kg}^{-1}$ (or $\pm 30 \%$ ) up to $2.5 \mathrm{~km}$ and RMS values are smaller than $3 \mathrm{~g} \mathrm{~kg}^{-1}$ (or 50\%). High bias values are often found in coincidence with high values of RMS, especially for daytime comparisons which may be associated with the large random error affecting BASIL measurements.

Figure 6 shows the profiles of mean biases and RMS deviations obtained using all 25 profile-to-profile intercomparisons. Mean absolute bias values are within $\pm 0.3 \mathrm{~g} \mathrm{~kg}^{-1}$, while mean relative bias is found to increase with altitude with the alternation of positive and negative values (maximum value $=-20 \%$ ). The mean RMS deviation shows a general increasing trend with height above the planetary boundary layer (PBL) (from 10 to 20\%) which is probably related to the height-dependent random error affecting BASIL measurements. Large RMS values within the $\mathrm{PBL}$ - up to $20 \%$ - are to be attributed to the large variability of the water vapour content within this height region for the considered comparisons.

There appears to be no evident dependency of the absolute and relative bias (correlation coefficient smaller than 0.1 ) and the absolute RMS deviation (correlation coefficient $=0.14$ ) on the minimum distance of the two measuring sensors (see Table II), as small and large bias and RMS deviation values are found for both small and large distances between the compared sensors. Instead, a slight dependency of relative RMS deviation on the minimum distance is found, with data being fitting by a straight line (not shown here) with a positive slope of $1.3 \% \mathrm{~km}^{-1}$ and a correlation coefficient of 0.44 . Higher correlation coefficients are found when the cut-off distance is smaller than $10 \mathrm{~km}$.

Finally, the overall mean bias and RMS deviation for the whole $3.0 \mathrm{~km}$ interval from 0.5 to $3.5 \mathrm{~km}$ a.s.l. are $-2.13 \pm 0.52 \%$ (or $\left.-0.03 \pm 0.01 \mathrm{~g} \mathrm{~kg}^{-1}\right)$ and $32.89 \pm$ $1.21 \%$ (or $0.88 \pm 0.01 \mathrm{~g} \mathrm{~kg}^{-1}$ ), respectively. Negative values indicate that BASIL is drier than the CNRS DIAL. Performances are found to improve when we consider a lower $z_{\text {top }}$. In fact, when considering the vertical interval 0.5 to $3.0 \mathrm{~km}$ a.s.l., the overall mean bias and RMS deviation are found to be $0.93 \pm 0.57 \%$ and $15.56 \pm 0.29 \%$, respectively. The reduction of both bias and RMS deviation when considering a lower value of $z_{\text {top }}$ is most probably caused by the exclusion of data points in the upper vertical window $(3.0-3.5 \mathrm{~km})$, where random errors are higher, especially for daytime BASIL measurements. Furthermore, 

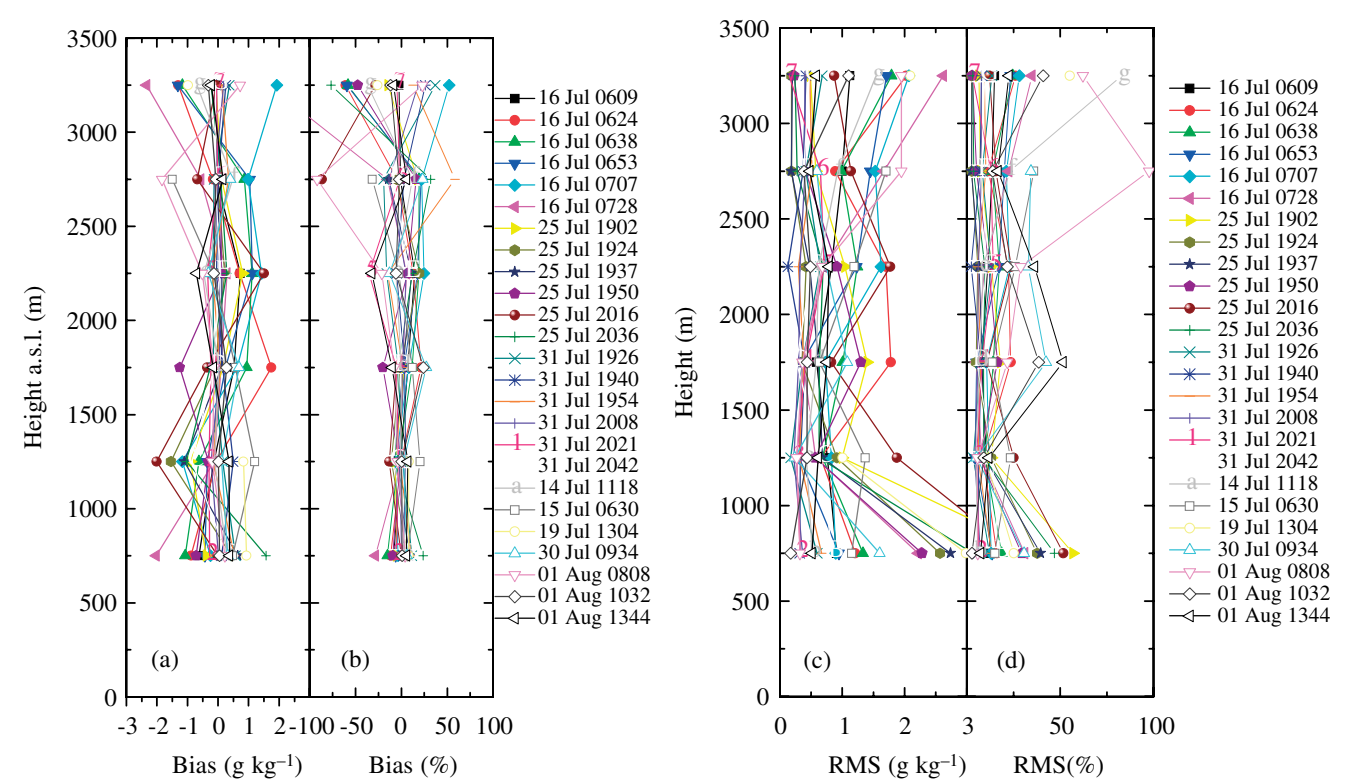

Figure 5. (a),(b) Bias and (c),(d) RMS deviations between BASIL and CNRS DIAL computed in the $500 \mathrm{~m}$ height intervals from 0.5 to $3.5 \mathrm{~km}$ a.s.l. for all 25 profile-to-profile intercomparisons in Table II. This figure is available in colour online at wileyonlinelibrary.com/journal/qj
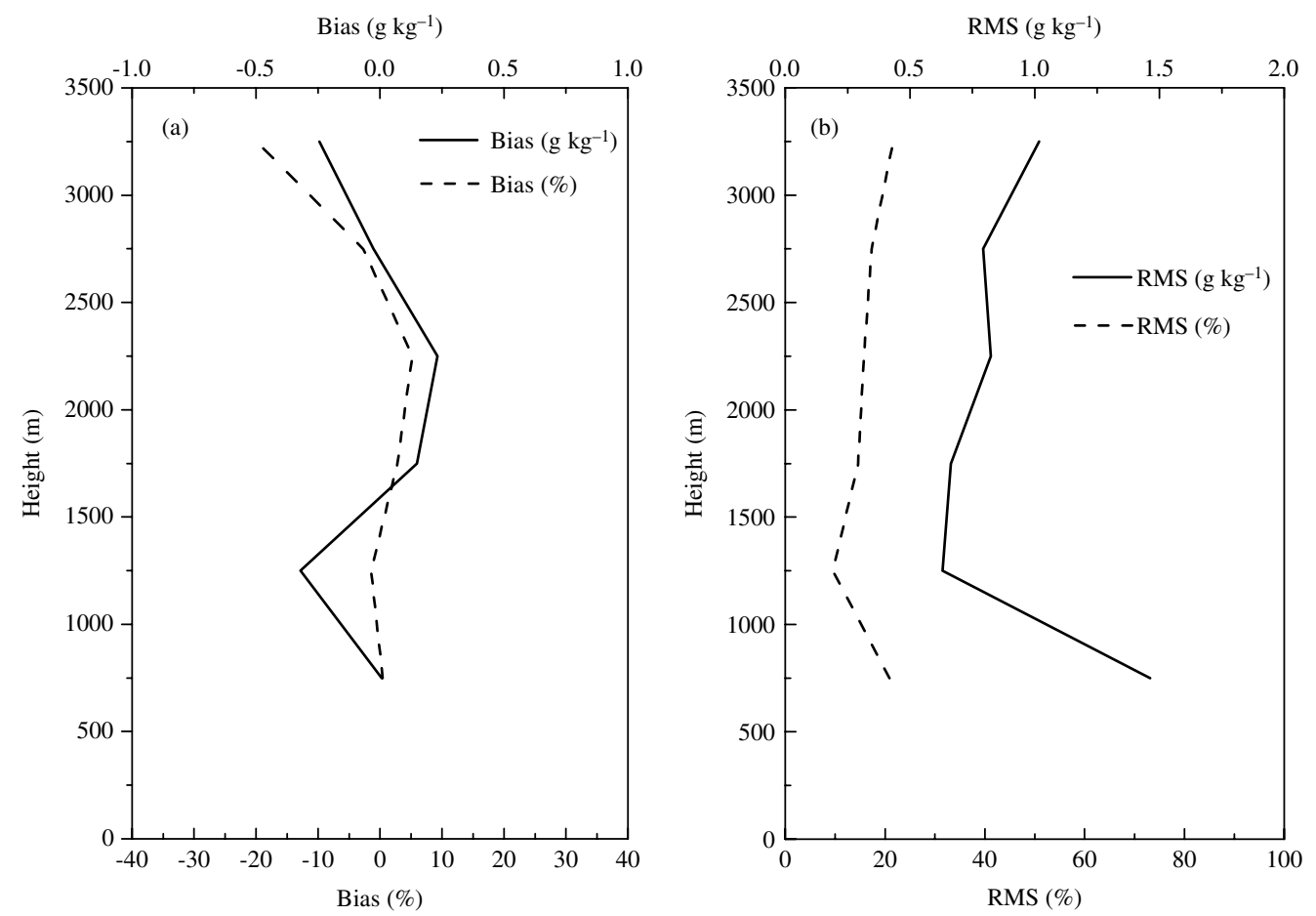

Figure 6. Profiles of mean bias (a) and RMS deviation (b) obtained considering all 25 BASIL vs. CNRS DIAL profile-to-profile intercomparisons in Table II.

when considering only those profiles from the two sensors within a distance of $5 \mathrm{~km}$, the overall mean bias and RMS deviation decrease to $-1.02 \pm 0.52 \%$ and $13.75 \pm 0.28 \%$, respectively.

The results reveal a very good agreement between BASIL and CNRS DIAL, especially when considering the different locations and integration times of the two sensors, the fact that CNRS DIAL data have been converted into mixing ratio based on pressure and temperature information from a reference atmospheric model and that BASIL relies on an external calibration. Finally, we wish to point out that only 8 out of the 25 intercomparison are at night-time, while the remaining 17 are in daytime. When considering only the night-time comparisons, the analysis can be extended up to the CNRS DIAL flight altitude $(\sim 4.5 \mathrm{~km})$. In this case, the overall mean bias and RMS deviation for the vertical interval from 0.5 to $4.5 \mathrm{~km}$ a.s.l. are $0.45 \pm 0.62 \%\left(-0.04 \pm 0.01 \mathrm{~g} \mathrm{~kg}^{-1}\right)$ and $10.76 \pm 0.28 \%$ $\left(0.69 \pm 0.02 \mathrm{~g} \mathrm{~kg}^{-1}\right)$, respectively.

\subsubsection{BASIL vs. DLR DIAL}

A list of the possible intercomparisons between BASIL and the DLR DIAL is given in Table III, where all overpasses within a maximum distance of $10 \mathrm{~km}$ are considered. Figure 7 shows an example of a comparison between BASIL and DLR 
Table III. Intercomparisons between BASIL and the DLR DIAL, considering a cut-off distance of $10 \mathrm{~km}$.

\begin{tabular}{lcccccc}
\hline No. & Date & Time (UTC) & Min. distance $(\mathrm{km})$ & BIAS $(\%)$ & RMS dev. $(\%)$ & Aircraft track vs. valley \\
\hline 1 & 18 July 2007 & 1605 & 8.9 & 0.10 & 7.67 & parallel \\
2 & 30 July 2007 & 1053 & 8.9 & -7.27 & 14.47 & parallel \\
3 & 30 July 2007 & 1153 & 9.1 & 8.19 & 12.13 & parallel \\
& & Overall & & $1.86 \pm 0.85$ & $11.47 \pm 0.71$ & \\
\hline
\end{tabular}

The given time corresponds to the minimum distance between the two sensors. The mean bias and RMS deviation have been determined over the vertical interval $0.5-3.5 \mathrm{~km}$ a.s.l.

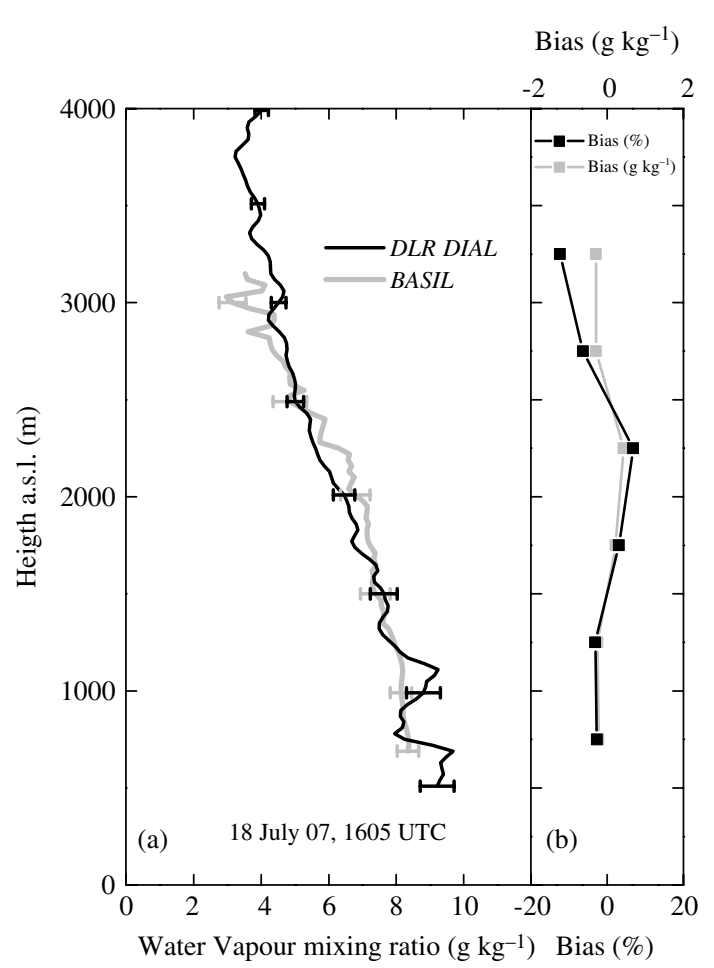

Figure 7. (a) Comparison between BASIL and DLR DIAL at 1605 UTC on 18 July 2007, and (b) deviations, both absolute and relative, between the two sensors.

DIAL at 1605 UTC on 18 July 2007, with a minimum distance between the two sensors of $8.9 \mathrm{~km}$. Again, the right portion of the figure illustrates the deviations between the two sensors. To compute deviations, DLR DIAL data have been interpolated to BASIL data heights. The two profiles show a very good agreement with the deviation between the two sensors being $0.4 \mathrm{~g} \mathrm{~kg}^{-1}$ in the altitude region $2.0-2.5 \mathrm{~km}$, while it is not exceeding $0.25 \mathrm{~g} \mathrm{~kg}^{-1}$ elsewhere. None of the bias values in Table III exceeds 9\%, while mean RMS values do not exceed $15 \%$.

All overpasses in Table III are parallel to the valley and this possibly justifies the smaller mean bias values observed in the BASIL vs. DLR DIAL intercomparison with respect to the BASIL vs. CNRS DIAL intercomparison, where all profile-toprofile comparisons except one are based on aircraft tracks perpendicular to the valley. Figure 8 shows the bias and RMS deviations between BASIL and DLR DIAL in the $500 \mathrm{~m}$ height intervals from 0.5 to $3.5 \mathrm{~km}$ a.s.l. for the three profileto-profile intercomparisons listed in Table III. Bias values are within $\pm 0.5 \mathrm{~g} \mathrm{~kg}^{-1}$ (or $\pm 10 \%$ ) up to $2.5 \mathrm{~km}$, while slightly larger values are present above. Values of RMS are smaller than $0.5 \mathrm{~g} \mathrm{~kg}^{-1}$ (or 15\%) up to $2.5 \mathrm{~km}$ and increase above, again as a result of the large random error affecting BASIL measurements. In this respect, we wish to recall that the three intercomparisons are all carried out during daytime when Raman lidar performances are sensitively degraded from the presence of high solar background radiation. Figure 9 shows the profiles of mean biases and RMS deviations obtained considering the three BASIL vs. DLR DIAL profileto-profile intercomparisons. Mean absolute bias values are within $\pm 0.25 \mathrm{~g} \mathrm{~kg}^{-1}$, while the mean relative bias is found to increase with altitude up to $6 \%$ with alternating positive and negative values. Here and above, positive values indicate that BASIL is wetter than DLR DIAL. The mean RMS deviation is smaller than $0.4 \mathrm{~g} \mathrm{~kg}^{-1}$ (or $8 \%$ ) up to $2.5 \mathrm{~km}$ and increases above.

The overall mean bias between these two profiling sensors is $1.87 \pm 0.85 \%\left(0.02 \pm 0.23 \mathrm{~g} \mathrm{~kg}^{-1}\right)$ in the altitude region $0.5-3.5 \mathrm{~km}$, while RMS has a mean value of $11.47 \pm 0.71 \%$ $\left(1.07 \pm 0.01 \mathrm{~g} \mathrm{~kg}^{-1}\right)$ in the same altitude region.

An intercomparison between BASIL and different sensors capable of measuring the water column content was also carried out. Data from a GPS receiver, a microwave radiometer, together with vertically integrated data from radiosondes, were considered for this purpose. A detailed description of these results will be provided in a forthcoming paper. All these sensors are found to be in good agreement with BASIL over extended time periods. Based on the available datasets for BASIL, GPS and the two airborne DIALs, and putting equal weight on the data reliability of each instrument (as none of them can be $a$ priori assumed to be more accurate than the others), and imposing the summation of all mutual biases between lidar pairs to be zero, it results in the bias values of BASIL, DLR DIAL, CNRS DIAL and GPS being $-0.12 \%,-1.98 \%, 2.01 \%$ and $0.10 \%$, respectively, as sketched in Figure 10. It is noteworthy that relative bias is more appropriate than the absolute bias to describe mutual deviations between lidar instruments because potential systematic errors in the system calibration for both Raman lidars and DIALs approximately scale with the amount of water vapour.

\subsection{UHOH DIAL vs. airborne DIALs}

\subsubsection{UHOH DIAL vs. CNRS DIAL}

A list of the possible intercomparisons between $\mathrm{UHOH}$ DIAL and the CNRS DIAL is given in Table IV, where again all overpasses within a maximum distance of $10 \mathrm{~km}$ are considered. Here, as in all other DIAL-to-DIAL comparisons, profiles are expressed in terms of water vapour number density. After data quality control and operation mode check, a total of three intercomparisons are left, all during daytime. 

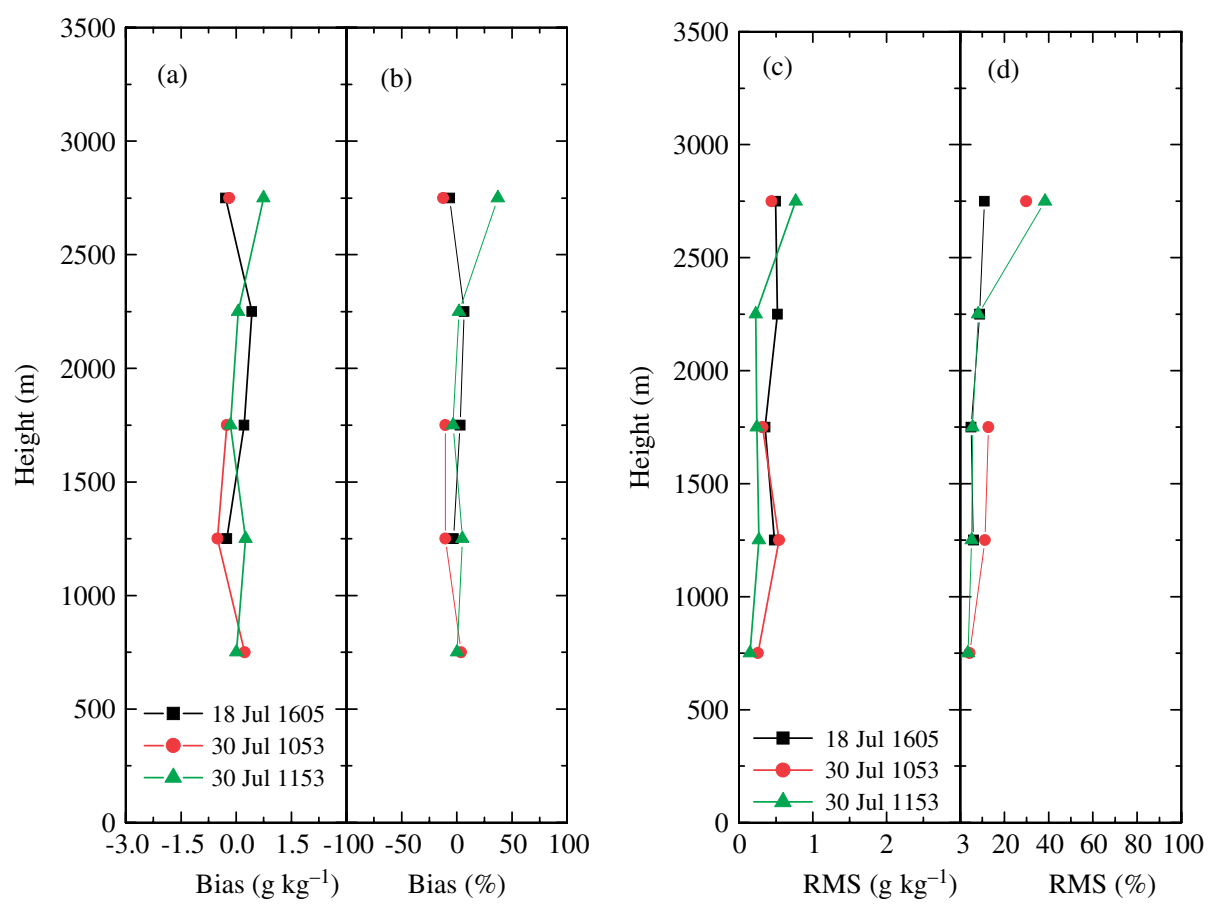

Figure 8. (a),(b) Bias and (c),(d) RMS deviations between BASIL and DLR DIAL computed in the $500 \mathrm{~m}$ height intervals from 0.5 to $3.5 \mathrm{~km}$ a.s.l. for the three profile-to-profile intercomparisons in Table III. This figure is available in colour online at wileyonlinelibrary.com/journal/qj
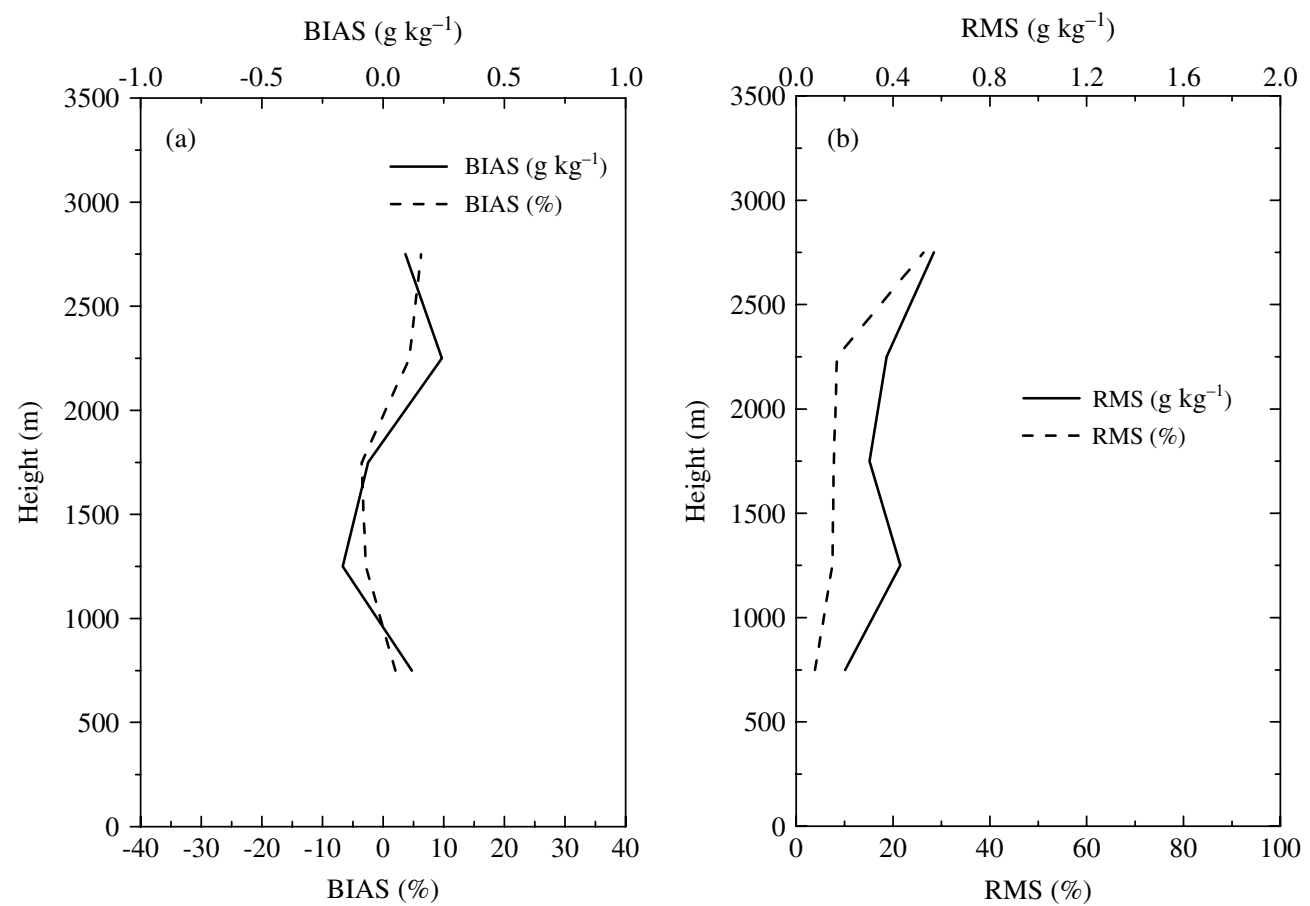

Figure 9. Profiles of mean bias (a) and RMS deviation (b) obtained from the three BASIL vs. DLR DIAL profile-to-profile intercomparisons in Table III.

Table IV. Intercomparisons between UHOH DIAL and the CNRS DIAL, using a cut-off distance of $10 \mathrm{~km}$.

\begin{tabular}{lcccccc}
\hline No. & Date & Time (UTC) & Min. distance $(\mathrm{km})$ & BIAS (\%) & RMS dev. (\%) & $\begin{array}{c}\text { Aircraft track } \\
\text { vs. orography }\end{array}$ \\
\hline 1 & 15 July 2007 & 0630 & 3.78 & 4.65 & 8.64 & parallel \\
2 & 01 August 2007 & 1346 & 4.33 & 4.73 & 14.02 & cross \\
3 & 01 August 2007 & 1620 & 2.46 & -2.02 & 30.85 & cross \\
& & & & $-\mathbf{3 . 2 0} \pm \mathbf{0 . 8 4}$ & $\mathbf{1 5 . 9 7} \pm \mathbf{0 . 8 1}$ & \\
\hline
\end{tabular}

The given time corresponds to the minimum distance between the two sensors. The mean bias and RMS deviation have been determined over the vertical interval $1.5-4.5 \mathrm{~km}$ a.s.l. 


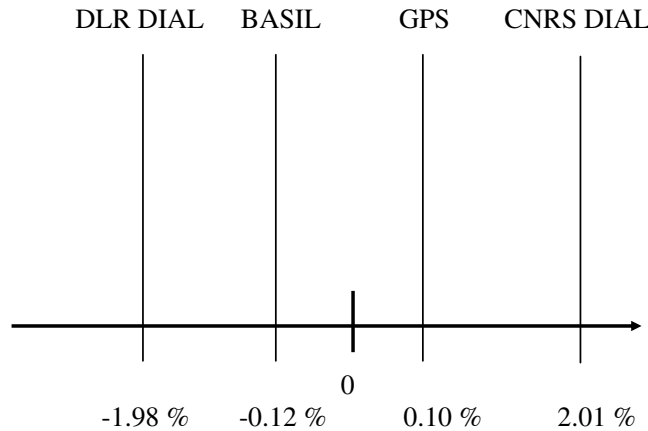

Figure 10. Resulting bias values after putting equal weight on all water vapour sensors considered in the figure, i.e. BASIL, CNRS DIAL, DLR DIAL and GPS.

Figure 11 shows an example of a comparison between UHOH DIAL and CNRS DIAL at 0630 UTC on 15 July 2007, with a minimum distance between the two sensors of $3.78 \mathrm{~km}$. This is the only intercomparison case for which the aircraft flew approximately parallel to the orography. The other two cases are with zonal tracks (east-west) of the aircraft. In this direction, there is a steep gradient in orography close to the UHOH DIAL site (about $900 \mathrm{~m}$ altitude difference over less than $10 \mathrm{~km}$ ). The right panel of Figure 11 shows the deviation between the two sensors. To compute deviations, CNRS DIAL data have been interpolated to $\mathrm{UHOH}$ DIAL data heights. Considering the gradient in orography, the two profiles show a very good agreement. A bias value of $4.65 \%$ is found in this case. Note the different slope in the humidity profile observed by the UHOH DIAL and the CNRS DIAL at $\sim 3800 \mathrm{~m}$ a.s.l, i.e. at the top of a residual boundary layer, where a strong humidity gradient is present. This difference is the effect of the different air masses being sampled by the two sensors; in fact, CNRS DIAL data are averaged over a horizontal distance of about $13 \mathrm{~km}$ which results in a smoother gradient compared to the one present in the local profile measured by the $\mathrm{UHOH}$ DIAL. These sampling effects also explain the relatively high RMS deviations between the sensors.

The mean bias and RMS deviation over the vertical interval $1.5-4.5 \mathrm{~km}$ for all comparison cases are also listed in Table IV. None of the mean bias values exceeds $\pm 5 \%$, while mean RMS values do not exceed $31 \%$. Bias and RMS deviation between the two sensors for all intercomparisons have been computed for the $500 \mathrm{~m}$ height intervals from 1.5 to $4.5 \mathrm{~km}$ a.s.l. (Figure 12). Bias values are in the range $-1.6 \times 10^{22}$ to $+0.3 \times 10^{22} \mathrm{~m}^{-3}$ (or -11 to $+19 \%$ ), while values of RMS are smaller than $2 \times 10^{22} \mathrm{~m}^{-3}$ (or 35\%).

The profiles of the mean bias and RMS deviation for the three considered intercomparisons are illustrated in Figure 13. Here, negative values indicate that $\mathrm{UHOH}$ DIAL is drier than CNRS DIAL. Bias values are within $\pm 1 \times 10^{22} \mathrm{~m}^{-3}$ (or $\pm 15 \%$ ). Larger relative bias values are found at the top height where the statistical uncertainty of the data is larger. A similar trend is found for the mean relative RMS deviation which is found to increase with height from a value of $8 \%$ at $2-2.5 \mathrm{~km}$ to a value of $27 \%$ at $4-4.5 \mathrm{~km}$. The overall mean bias and RMS deviation for the whole $3.0 \mathrm{~km}$ interval from 1.5 to $4.5 \mathrm{~km}$ a.s.l. are $-3.20 \pm 0.84 \%$ (or $-0.37 \pm 0.05) \times 10^{22} \mathrm{~m}^{-3}$ and $15.97 \pm 0.81 \%$ (or $-0.86 \pm 0.04) \times 10^{22} \mathrm{~m}^{-3}$, respectively.

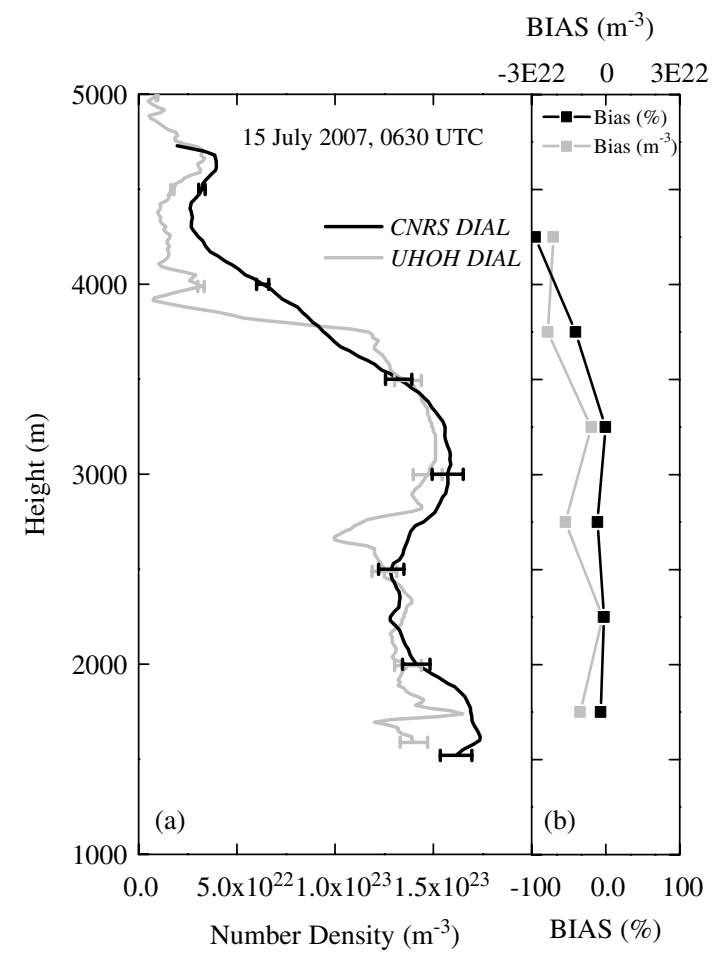

Figure 11. (a) Comparison between UHOH DIAL and CNRS DIAL at 1346 UTC on 1 August 2007, and (b) deviations, both absolute and relative, between the two sensors.

\subsubsection{UHOH DIAL vs. DLR DIAL}

The four possible comparisons between UHOH DIAL and the DLR DIAL, all during daytime, are within a minimum distance of $1.1-1.7 \mathrm{~km}$ (Table V). DLR DIAL measurements are based on an integration time of $4 \mathrm{~s}$. Figure 14 illustrates an example of a comparison between UHOH DIAL and DLR DIAL at 0645 UTC on 15 July 2007, with a minimum distance between the two sensors of $1.7 \mathrm{~km}$. Again, the right panel of the figure shows the deviation between the two sensors. To compute deviations, DLR DIAL data have been interpolated to UHOH DIAL data heights. The two profiles show a very good agreement with deviations not exceeding $\pm 1 \times 10^{22} \mathrm{~m}^{-3}$. Larger differences are again found near the top of the moist layer where different slopes were sampled. The mean bias and RMS deviation over the vertical interval $1.5-4.5 \mathrm{~km}$ for all comparison cases are also listed in Table V. None of the biases exceed $\pm 10 \%$, while mean RMS values do not exceed $30 \%$. All overpasses in Table $\mathrm{V}$ are zonal, except for 15 August 2007, 0645 UTC, which is meridional, i.e. parallel to the orography, and it is characterized by a small bias value of $1.24 \%$.

Bias and RMS deviation between the two sensors for all intercomparisons have been computed for all $500 \mathrm{~m}$ height intervals from 1.5 to $4.5 \mathrm{~km}$ a.s.l. (Figure 15). With the exception of few points, bias values are within $\pm 25 \%$. Here, positive values indicate that UHOH DIAL is wetter than DLR DIAL. The profiles of mean bias and RMS deviation obtained considering all four profile-to-profile intercomparisons are reported in Figure 16. The mean bias is in the range -12 to $+17 \%$ (or $-1.45 \times 10^{22} \mathrm{~m}^{-3}$ to $1.71 \times 10^{22} \mathrm{~m}^{-3}$ ). The mean relative and absolute RMS deviation show values smaller than $40 \%$ and $3 \times 10^{22} \mathrm{~m}^{-3}$, respectively. The overall mean bias and RMS deviation for the whole $3.0 \mathrm{~km}$ interval from 1.5 to $4.5 \mathrm{~km}$ a.s.l. are $0.83 \pm 0.74 \%$ (or $0.06 \pm 0.08$ ) 

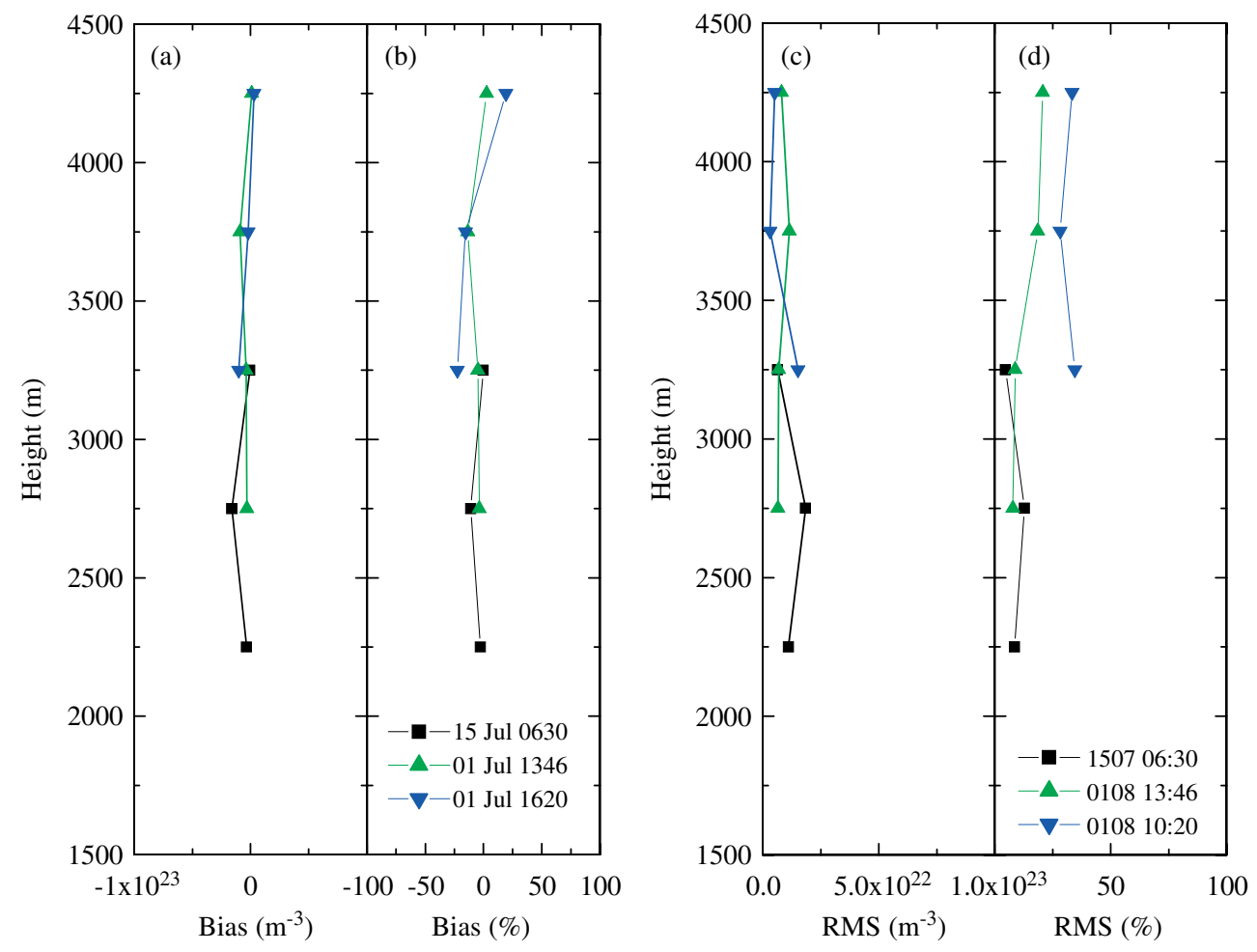

Figure 12. (a),(b) Bias and (c),(d) RMS deviations between UHOH DIAL and CNRS DIAL computed in the $500 \mathrm{~m}$ height intervals from 1.5 to $4.5 \mathrm{~km}$ a.s.l. for the three profile-to-profile intercomparisons in Table IV. This figure is available in colour online at wileyonlinelibrary.com/journal/qj
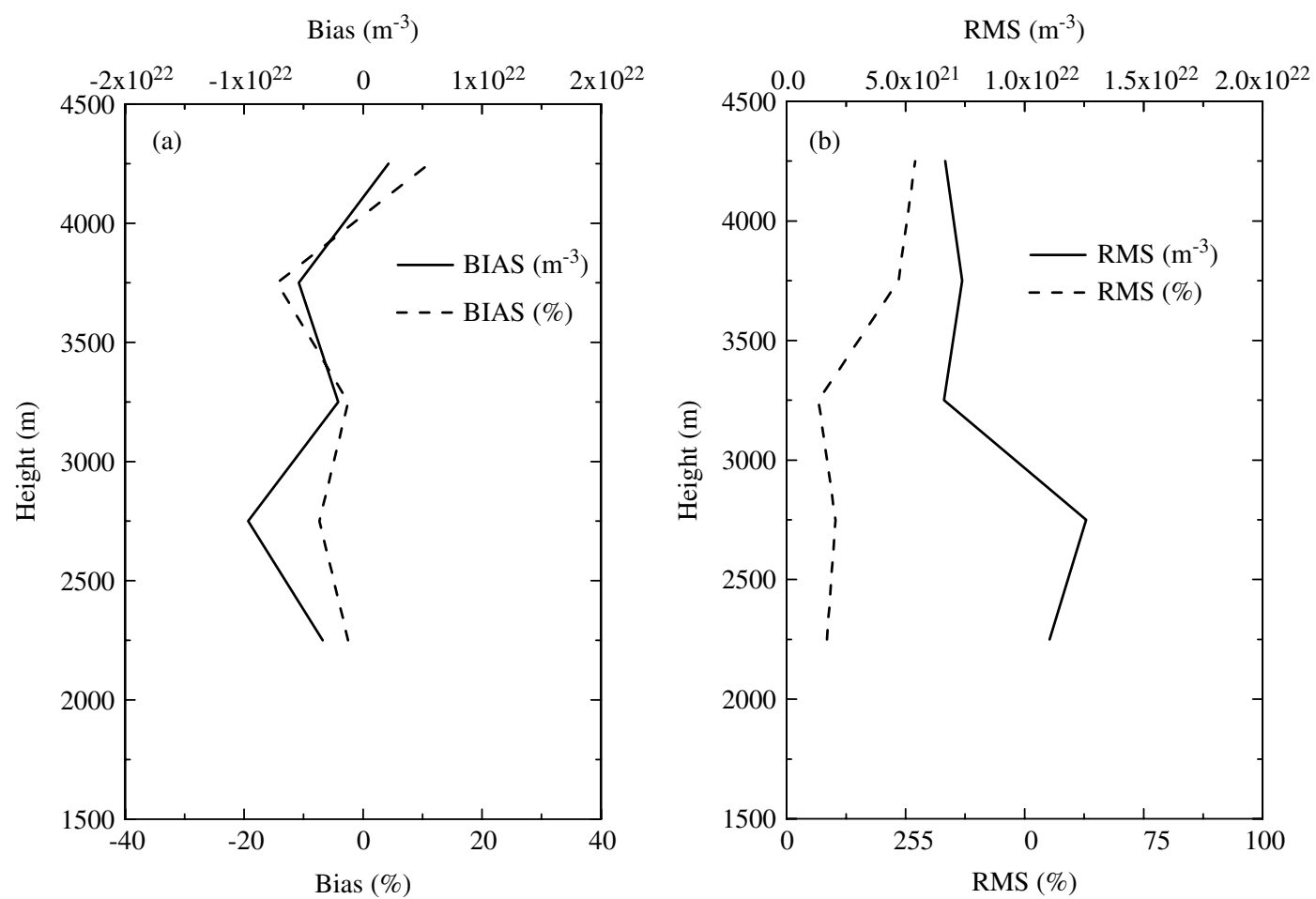

Figure 13. Profiles of mean bias (a) and RMS deviation (b) obtained considering the three UHOH DIAL vs. CNRS DIAL profile-to-profile intercomparisons in Table IV.

$\times 10^{22} \mathrm{~m}^{-3}$ and $21.51 \pm 0.73 \%$ (or $\left.2.14 \pm 0.06\right) \times 10^{22} \mathrm{~m}^{-3}$ respectively. Under the special circumstances, which are connected to the intercomparisons of the UHOH DIAL and the airborne DIALs at the mountainous site with surrounding complex orography, and keeping in mind that all these intercomparisons were carried out during daytime, we consider the mean bias values found here as satisfactory.

\subsection{BERTHA vs. CNRS DIAL}

Nine daytime overpasses were performed by the DLR Falcon over BERTHA. However, during COPS, BERTHA operated the water vapour channels only at night-time. A total of six night-time intercomparisons between BERTHA and CNRS DIAL were obtained by using all overpasses within a 
Table V. Intercomparisons between UHOH DIAL and the DLR DIAL, using a cut-off distance of $10 \mathrm{~km}$.

\begin{tabular}{lcccccc}
\hline No. & Date & Time (UTC) & Min. distance $(\mathrm{km})$ & BIAS $(\%)$ & RMS dev. (\%) & Aircraft track vs. orography \\
\hline 1 & 15 July 2007 & 0645 & 1.67 & 1,24 & 9.30 & parallel \\
2 & 15 July 2007 & 0721 & 1.50 & 5.27 & 19.67 & cross \\
3 & 26 July 2007 & 1006 & 1.66 & -9.74 & 29.73 & cross \\
4 & 26 July 2007 & 1042 & 1.08 & 0.96 & 22.38 & cross \\
& & & $\mathbf{0 . 8 3} \pm \mathbf{0 . 7 4}$ & $\mathbf{2 1 . 5 1} \pm \mathbf{0 . 7 3}$ & \\
\hline
\end{tabular}

The given time corresponds to the minimum distance between the two sensors. The mean bias and RMS deviation have been determined over the vertical interval $1.5-4.5 \mathrm{~km}$ a.s.l.

Table VI. Intercomparisons between BERTHA Raman lidar and the CNRS DIAL, using a cut-off distance of $10 \mathrm{~km}$.

\begin{tabular}{lccccc}
\hline No. & Date & Time $($ UTC $)$ & Min. distance $(\mathrm{km})$ & BIAS $(\%)$ & RMS dev. $(\%)$ \\
\hline 1 & 31 July 2007 & 1926 & 9.89 & -2.33 & 22.53 \\
2 & 31 July 2007 & 1940 & 9.61 & -10.09 & 18.84 \\
3 & 31 July 2007 & 1954 & 9.93 & 7.70 & 18.92 \\
4 & 31 July 2007 & 2008 & 9.35 & -3.58 & 28.08 \\
5 & 31 July 2007 & 2021 & 9.08 & -6.15 & 19.31 \\
6 & 31 July 2007 & 2042 & 9.59 & -11.37 & 27.18 \\
& & Overall & & $\mathbf{4 . 3 7} \pm \mathbf{0 . 8 3}$ & $\mathbf{2 3 . 0 0} \pm \mathbf{0 . 6 9}$ \\
\hline
\end{tabular}

The given time corresponds to the minimum distance between the two sensors. The mean bias and RMS deviation have been determined over the vertical interval $0.5-4.5 \mathrm{~km}$ a.s.l.

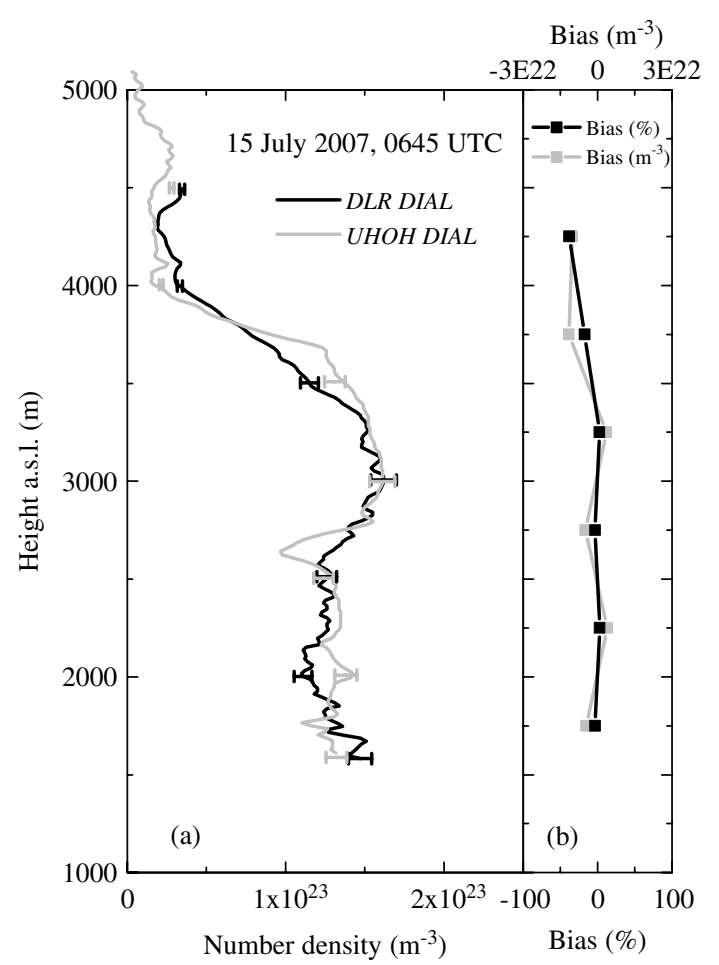

Figure 14. (a) Comparison between UHOH DIAL and DLR DIAL at 0645 UTC on 15 July 2007, and (b) deviations, both absolute and relative, between the two sensors.

maximum distance of $10 \mathrm{~km}$ from the ground-based lidar. They are listed in Table VI along with the minimum distance between the two instruments and the mean bias and RMS deviation measured over the vertical interval $0.5-4.5 \mathrm{~km}$.

Figure 17 illustrates an example of a comparison between BERTHA and CNRS DIAL at 1926 UTC on 31 July 2007 with a minimum distance between the two sensors of $9.89 \mathrm{~km}$. Again, the right portion of Figure 17 shows the deviations between the two sensors. To compute deviations, CNRS DIAL data have been interpolated to the BERTHA heights. The two profiles show a very good agreement, with deviations not exceeding $0.25 \mathrm{~g} \mathrm{~kg}^{-1}$. None of the mean bias values in Table VI exceeds $\pm 12 \%$, while mean RMS values do not exceed $30 \%$. In this case, the table is not reporting whether the aircraft track is parallel or perpendicular to the valley as in fact most of the overpasses were made in a non-levelled way while the aircraft was turning between two parallel legs (F3 and F4).

For all intercomparisons, bias and RMS deviation between the two sensors have been computed in the $500 \mathrm{~m}$ height intervals from 0.5 to $4.5 \mathrm{~km}$ a.s.l. (Figure 18). Bias values are within $\pm 1 \mathrm{~g} \mathrm{~kg}^{-1}$ (or $\pm 50 \%$ ), while values of RMS do not exceed $1.2 \mathrm{~g} \mathrm{~kg}^{-1}$ (or 60\%).

Figure 19 shows the profiles of mean biases and RMS deviations obtained considering all six profile-to-profile intercomparisons. The mean relative bias is found to increase with altitude from a slightly negative value of $-3 \%$ in the lower height interval to $-30 \%$ in the $2.5-3.0 \mathrm{~km}$ interval. The presence of large bias values in the $2.5-3.0 \mathrm{~km}$ interval, i.e. at the top of the boundary layer, is to be attributed to the different gradient in BERTHA and the CNRS DIAL data in this altitude interval. The gradient is smoother in the CNRS DIAL data, probably as a result of the averaging of the CNRS DIAL data over a larger horizontal path. The mean absolute bias shows a much smaller altitude variability with values in the range of -0.3 to $0.1 \mathrm{~g} \mathrm{~kg}^{-1}$. The mean relative RMS is found to increase with altitude as a result of the increasing random error affecting BERTHA measurements (with values close to $50 \%$ ), with largest values in the height interval $2.5-3.0 \mathrm{~km}$, i.e. at the top of the boundary layer, where the variability of the water vapour content is larger. Mean bias is $-4.37 \pm 0.83 \%$ (or $-0.123 \pm 0.013 \mathrm{~g} \mathrm{~kg}^{-1}$ ) in the altitude $0.5-4.5 \mathrm{~km}$, while the mean RMS is $23.00 \pm 0.69 \%$ (or $0.662 \pm 0.018 \mathrm{~g} \mathrm{~kg}^{-1}$ ) in the same altitude interval. Here 

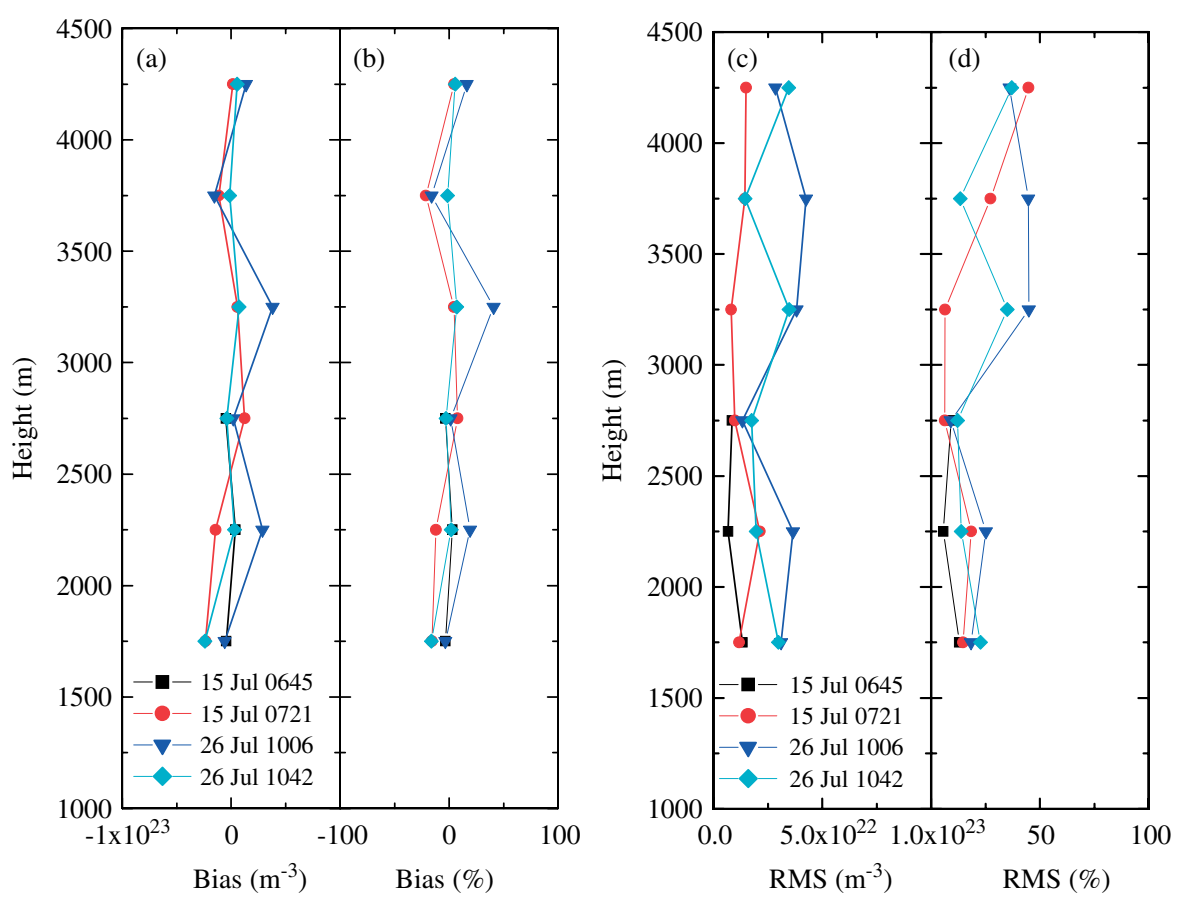

Figure 15. (a),(b) Bias and (c),(d) RMS deviations between UHOH DIAL and DLR DIAL computed in the $500 \mathrm{~m}$ height intervals from 1.5 to $4.5 \mathrm{~km}$ a.s.l. for the four profile-to-profile intercomparisons in Table V. This figure is available in colour online at wileyonlinelibrary.com/journal/qj
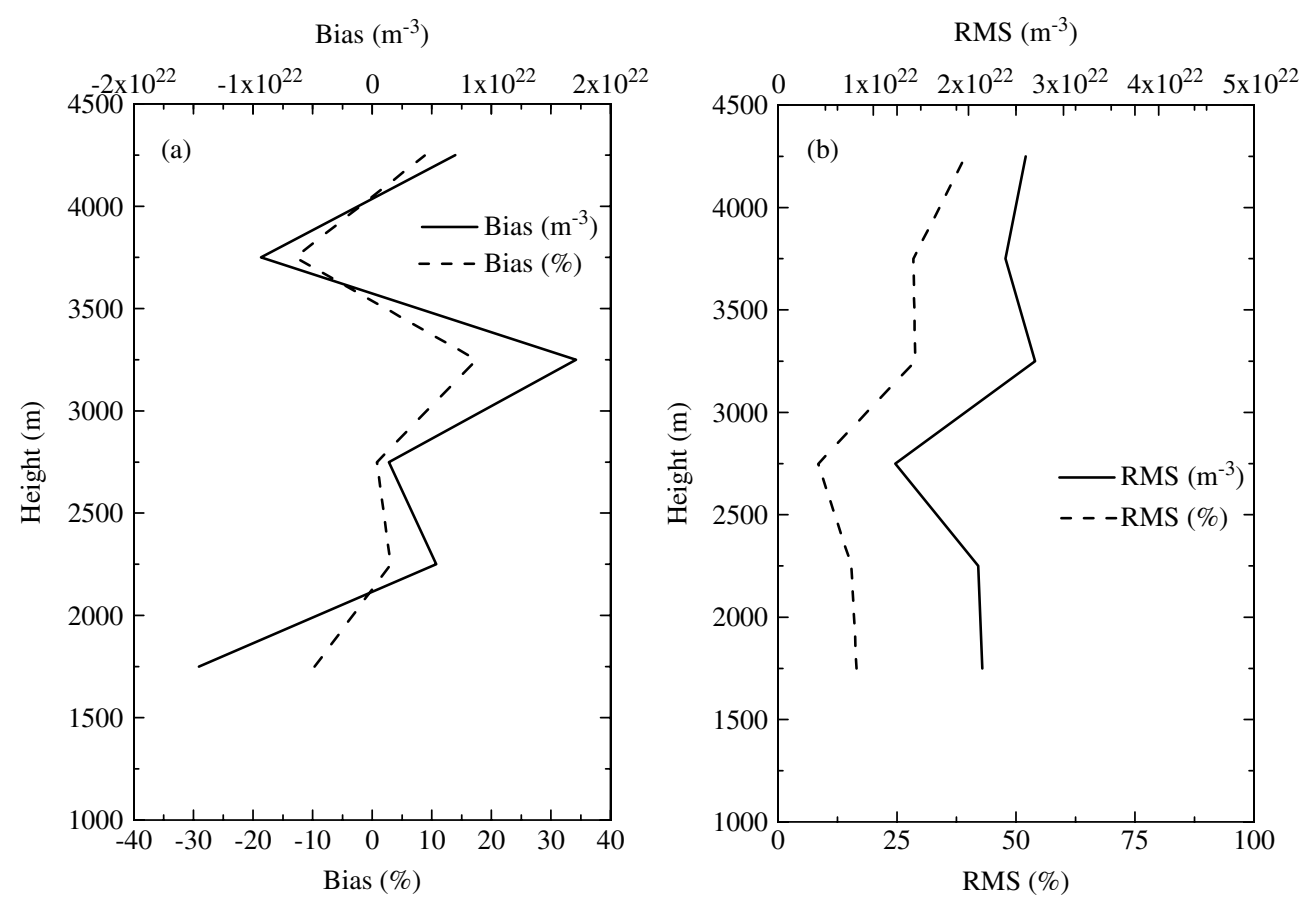

Figure 16. Profiles of mean bias (a) and RMS deviation (b) obtained using the four UHOH DIAL vs. DLR DIAL profile-to-profile intercomparisons in Table V.

and above, negative bias values indicate that BERTHA is drier than CNRS DIAL.

\subsection{IGN Raman Lidar vs. CNRS DIAL}

Comparisons between the IGN Raman lidar and DLR DIAL were not possible during COPS because the DLR DIAL performed only one overpass of supersite V, but the IGN Raman lidar was not operational at that time. Based on the available dataset, nine comparisons were possible between IGN Raman lidar and CNRS DIAL: six during night-time and three in the night-to-day transition period. These are listed in Table VII along with the minimum distance between the supersite and the flight path and the mean bias and RMS deviation measured over the vertical interval $0.5-4.5 \mathrm{~km}$. Because of the better performances of the IGN Raman lidar during the night, night-time comparisons are characterized by much smaller bias and RMS deviations than the comparisons performed in the night-to-day transition period.

Figure 20 illustrates an example of a comparison between IGN Raman lidar and CNRS DIAL at 2056 UTC on 31 July 
Table VII. Intercomparisons between IGN Raman lidar and the CNRS DIAL, using a cut-off distance of $10 \mathrm{~km}$.

\begin{tabular}{lccccc}
\hline No. & Date & Time (UTC) & Min. distance (km) & BIAS (\%) & RMS dev. (\%) \\
\hline 1 & 15 July 2007 & 0713 & 2.2 & 32.60 & 34.06 \\
2 & 16July 2007 & 0743 & 0.8 & 3.07 & 19.90 \\
3 & 25 July 2007 & 1918 & 2.9 & 5.34 & 38.20 \\
4 & 25 July 2007 & 2026 & 0.6 & 20.67 & 39.84 \\
5 & 25 July 2007 & 2050 & 0.92 & 26.70 & 45.39 \\
6 & 26 July 2007 & 0804 & 3.31 & -4.03 & 29.45 \\
7 & 31 July 2007 & 1920 & 0.86 & -7.92 & 30.28 \\
8 & 31 July 2007 & 2035 & 0.8 & 1.17 & 33.81 \\
9 & 31 July 2007 & 2056 & & & 26.50 \\
Overall & $\mathbf{5 . 1 1} \pm \mathbf{0 . 7 3}$ & $\mathbf{3 2 . 6 1 \pm 0 . 6 1}$ & & & \\
\hline
\end{tabular}

The given time corresponds to the minimum distance between the two sensors. The mean bias and RMS deviation have been determined over the vertical interval $0.5-4.5 \mathrm{~km}$ a.s.l.

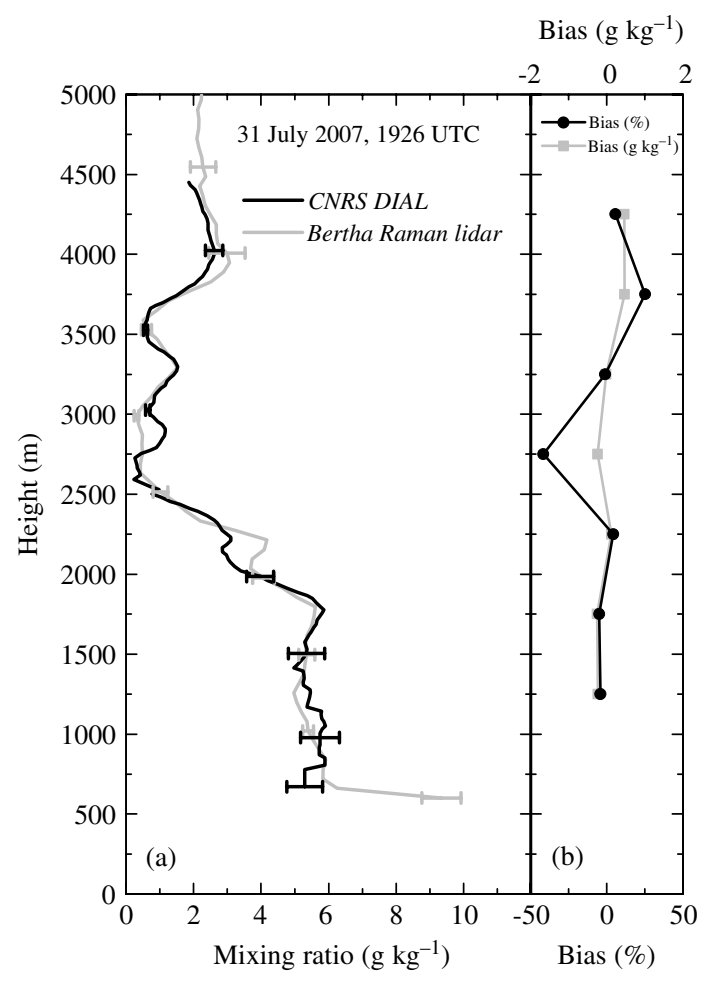

Figure 17. (a) Comparison between BERTHA Raman lidar and CNRS DIAL at 1926 UTC on 31 July 2007, and (b) deviations, both absolute and relative, between the two sensors.

2007 with a minimum distance between the two sensors of $0.8 \mathrm{~km}$. Again, the right portion of Figure 20 shows the deviations between the two sensors. To compute the deviations, CNRS DIAL data have been interpolated to the IGN Raman lidar data heights. The two profiles show a good agreement, with deviations not exceeding $1 \mathrm{~g} \mathrm{~kg}^{-1}$. Mean bias values in Table VII are as large as $32.6 \%$, while mean RMS values are always smaller than $50 \%$.

Bias and RMS deviations between the two sensors computed in the $500 \mathrm{~m}$ height intervals from 0.5 to $4.5 \mathrm{~km}$ a.s.l. are illustrated in Figure 21. Bias values are within $\pm 1 \mathrm{~g} \mathrm{~kg}^{-1}$ (or $\pm 50 \%$ ), with the only exception of a few values (as large as $2.5 \mathrm{~g} \mathrm{~kg}^{-1}$ ) observed during daytime. Again, the largest differences are found at the boundary layer transition zone between 1.5 and $2.5 \mathrm{~km}$ a.s.l. where the gradient is smoother in the CNRS DIAL data. This may be due to averaging of CNRS DIAL data over a larger horizontal path leading to a larger smoothing of the water vapour variability at the boundary-layer top. Values of RMS do not exceed $4 \mathrm{~g} \mathrm{~kg}^{-1}$ (or $80 \%$ ).

Figure 22 shows the profiles of mean biases and RMS deviations obtained using all nine profile-to-profile intercomparisons. Again, the mean relative bias shows a maximum variability in the $2.0-3.0 \mathrm{~km}$ interval (i.e. at the top and above the boundary layer) with values up to $\pm 15 \%$. The mean absolute bias shows a smaller altitude variability, with values in the range -0.2 to $1 \mathrm{~g} \mathrm{~kg}^{-1}$. The mean relative RMS is found to increase with altitude (with values as large as $60 \%$ in the height interval $2.5-3.0 \mathrm{~km}$, again as a result of the increasing random error and the large variability of the water vapour content in the proximity of the boundary-layer top). A large variability of both the mean relative and absolute RMS deviation is observed in the $2.0-3.0 \mathrm{~km}$ interval. The mean bias for all nine intercomparisons is $5.11 \pm 0.73 \%$ ( or $0.55 \pm 0.02 \mathrm{~g} \mathrm{~kg}^{-1}$ ) in the altitude range from $0.5-3.5 \mathrm{~km}$, while the mean RMS deviation is $32.61 \pm 0.61 \%\left(1.46 \pm 0.03 \mathrm{~g} \mathrm{~kg}^{-1}\right)$. In the case of night-time only comparisons (six intercomparisons in total), performances are found to appreciably improve, with the mean bias in the altitude range from $0.5-4.5 \mathrm{~km}$ becoming $3.18 \pm 0.77 \%$ (or $0.27 \pm 0.02 \mathrm{~g} \mathrm{~kg}^{-1}$ ). Here and above, positive values indicate that IGN Raman Lidar is wetter than CNRS DIAL.

\subsection{CNRS DIAL vs. DLR DIAL}

Five intercomparisons were possible over the COPS region (Table VIII) between the two airborne DIALs, i.e. the CNRS DIAL and the DLR DIAL, again considering a cut-off distance of $10 \mathrm{~km}$ (here considered as the distance between the footprints of the two systems). Table VIII also reports the minimum distance between the footprints of the airborne DIALs and the mean bias and RMS deviation measured over the vertical interval $0.5-4.0 \mathrm{~km}$. The table also reports if the flight tracks of the two airborne systems are crossing or parallel to each other and in the latter case whether they have the same or opposite directions. Three out of the five intercomparisons include data collected on parallel or coincident tracks while the remaining two are cross-track intercomparisons. We need to point out that water vapour heterogeneity plays a major role in the interpretation of the results of the airborne-to-airborne intercomparisons, 

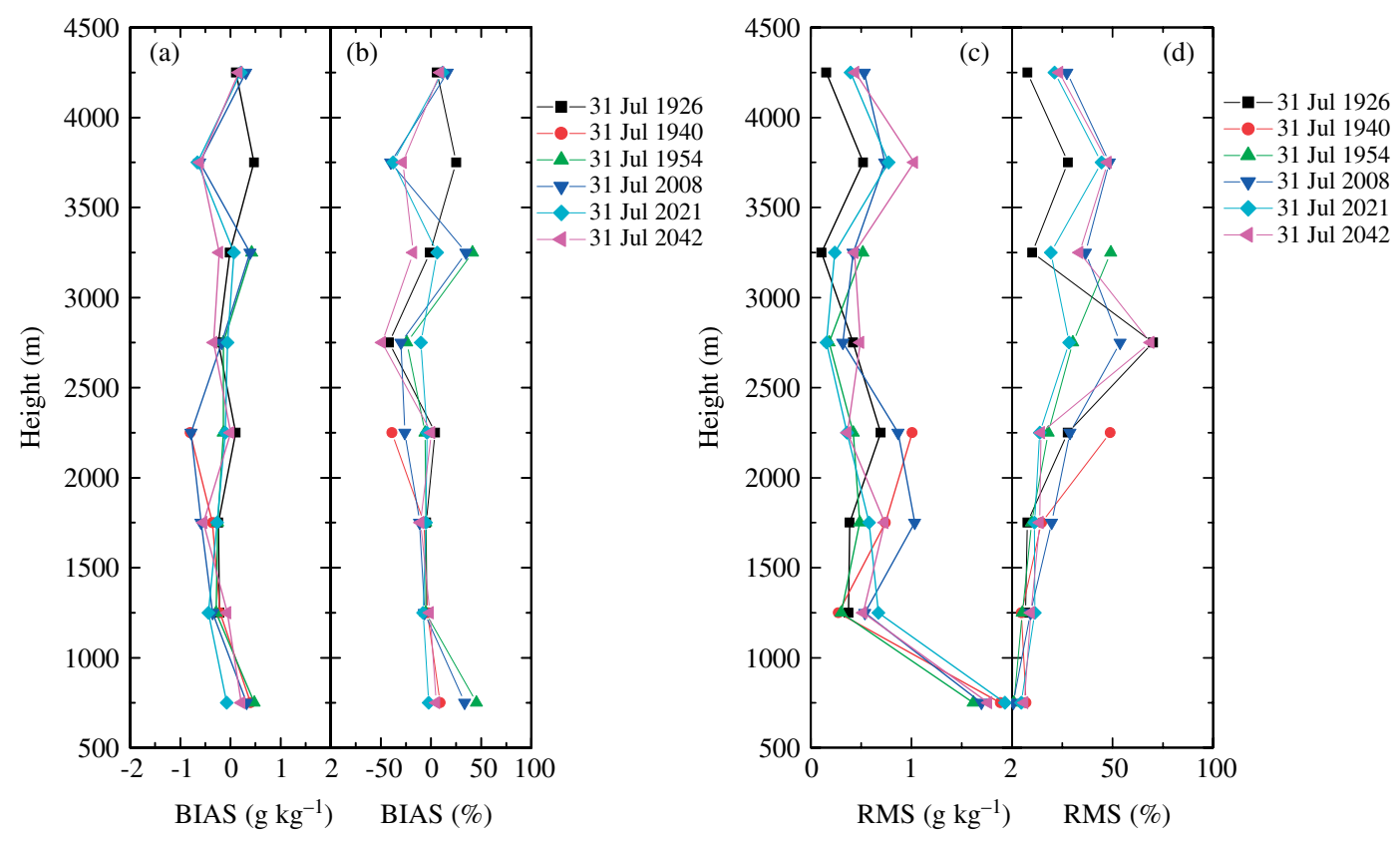

Figure 18. (a),(b) Bias and (c),(d) RMS deviations between BERTHA Raman lidar and the CNRS DIAL computed in the $500 \mathrm{~m}$ height intervals from 0.5 to $4.5 \mathrm{~km}$ a.s.l. for the six profile-to-profile intercomparisons in Table VI. This figure is available in colour online at wileyonlinelibrary.com/journal/qj
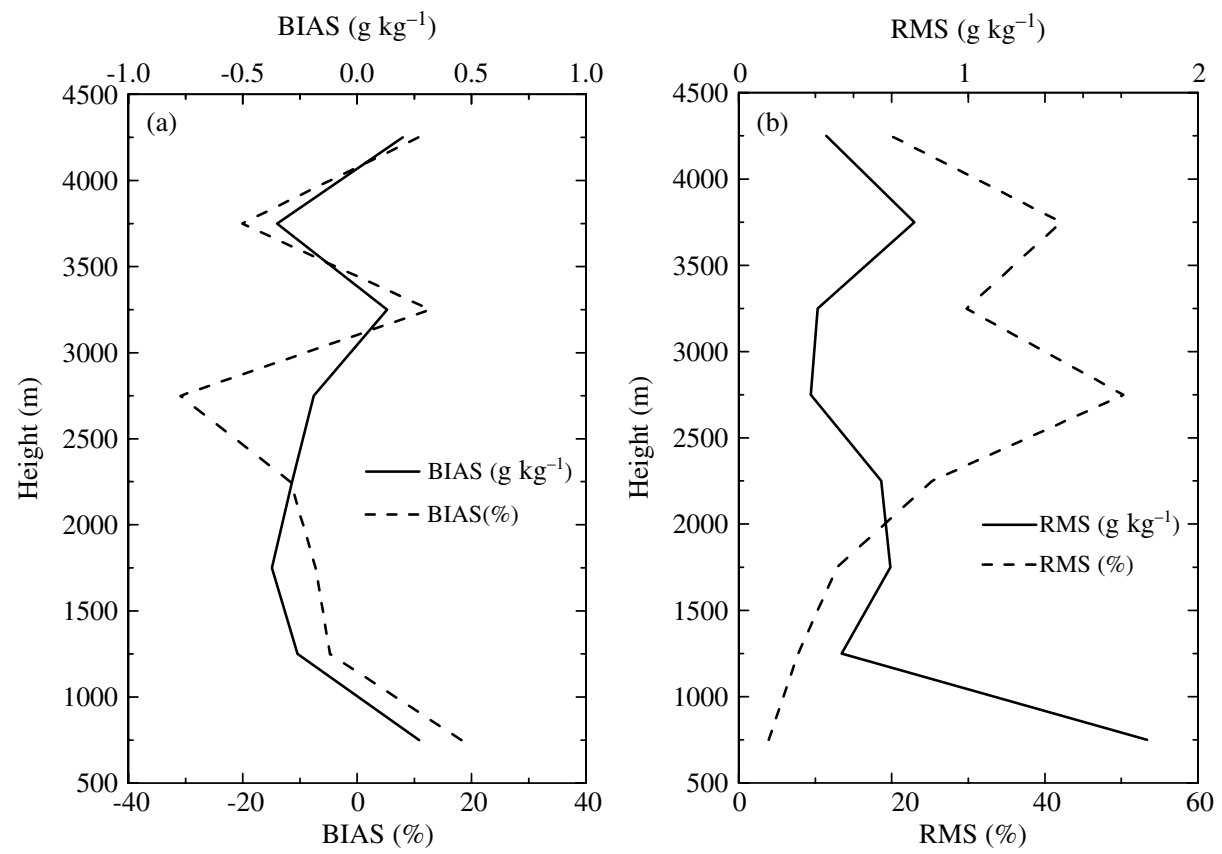

Figure 19. Profiles of mean bias (a) and RMS deviation (b) obtained using the six BERTHA Raman lidar vs. CNRS DIAL profile-to-profile intercomparisons in Table VI.

Table VIII. Intercomparisons between CNRS DIAL and the DLR DIAL using a cut-off distance of $10 \mathrm{~km}$.

\begin{tabular}{lcccccc}
\hline No. & Date & Time (UTC) & Min. distance $(\mathrm{km})$ & BIAS $(\%)$ & RMS dev. $(\%)$ & tracks \\
\hline 1 & 18 July 2007 & 1601 & 3.67 & 11.50 & 11.71 & coincident, opp. direction \\
2 & 18 July 2007 & 1617 & 9.82 & 7.46 & 23.55 & cross \\
3 & 30 July 2007 & 1041 & 6.62 & 9.97 & 44.30 & cross \\
4 & 30 July 2007 & 1153 & 2.48 & -6.99 & 14.59 & parallel, same direction \\
5 & 30 July 2007 & 1209 & 3.57 & -0.18 & 19.63 & parallel, same direction \\
& Overall & & $3.93 \pm 0.58$ & $19.37 \pm 0.61$ & \\
\hline
\end{tabular}

The given time corresponds to the minimum distance between the two sensors. The mean bias and RMS deviation have been determined over the vertical interval $0.5-4.0 \mathrm{~km}$ a.s.l. 


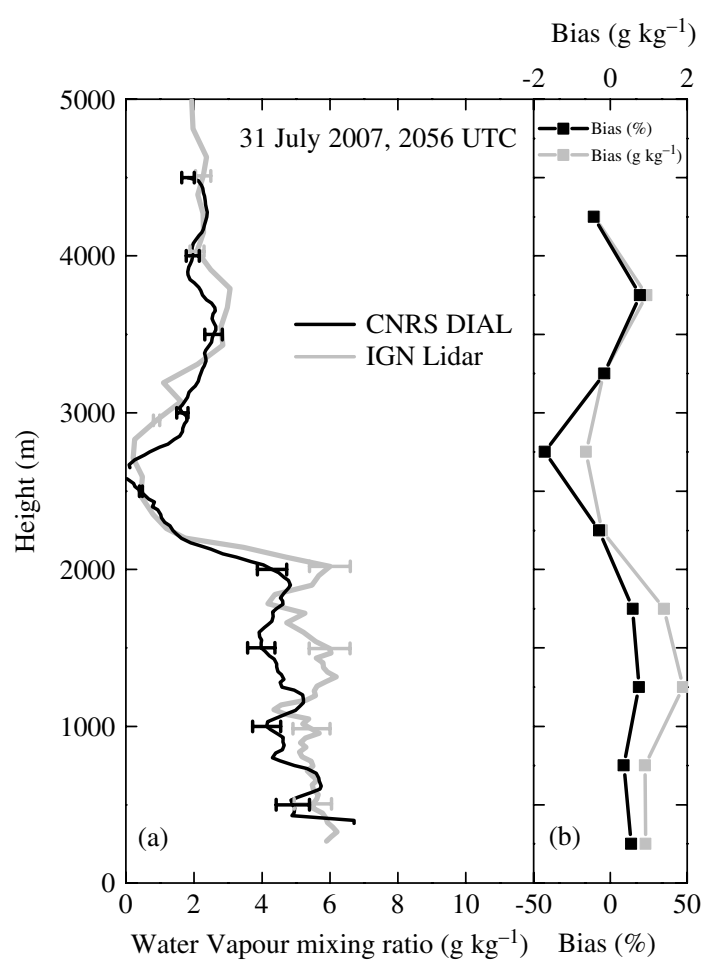

Figure 20. (a) Comparison between IGN Raman lidar and CNRS DIAL at 2056 UTC on 31 July 2007, and (b) deviations, both absolute and relative, between the two sensors.

with effects being generally more pronounced than for the ground-based-to-airborne lidar intercomparisons. These effects are mainly due to horizontal averaging and are more severe for isolated crossing points or approaches of the flight tracks. If the flight tracks are crossing, the sampled air masses differ more than the minimum distances of the aircraft's footprints may suggest. In the present intercomparison effort, in order to further reduce the statistical error affecting measurements (all carried out in the middle of the day, with a sun zenith angle smaller than $30^{\circ}$ ), we considered an integration time of $80-250 \mathrm{~s}$ and $70-180 \mathrm{~s}$ for the CNRS DIAL and DLR DIAL, respectively. Longer integration times are considered for those profiles collected at smaller zenith angles, again to guarantee comparable random errors (and thus statistical fluctuation) for all profiles.

Figure 23 shows an example of the intercomparison between these DIALs on 30 July 2007 at 1153 UTC with a minimum distance between the two sensors of $2.48 \mathrm{~km}$. Panel (a) shows the profiles from the two DIALs expressed in terms of mixing ratio (with panel (b) showing the corresponding deviations), while panel (c) shows the profiles expressed in terms of number density (with panel (d) illustrating the corresponding deviations). To compute deviations, CNRS DIAL and DLR DIAL data have been interpolated at the same heights. The two profiles show a very good agreement, with deviations not exceeding $\pm 1.5 \times 10^{22} \mathrm{~m}^{-3}$ (or $\pm 0.5 \mathrm{~g} \mathrm{~kg}^{-1}$ ). Mean bias values in Table VIII do not exceed $\pm 12 \%$ while mean RMS values are always smaller than $45 \%$. Table VIII indicates that smaller bias values are present when comparing data collected along parallel flight tracks and coincident directions for the two airborne systems.

Figure 24 illustrates the bias and RMS deviation between the number density profiles from the two sensors computed in the $500 \mathrm{~m}$ height intervals from 0.5 to $4.0 \mathrm{~km}$ a.s.l. Bias values are within $\pm 5 \times 10^{22} \mathrm{~m}^{-3}$ (or $\pm 25 \%$ ) except in a few instances. The largest absolute bias and RMS values are found within the boundary layer, while the largest relative bias and RMS values are observed in the upper levels.

Figure 25 shows the profiles of the mean bias and RMS deviation obtained considering all five profile-to-profile intercomparisons. Mean relative and absolute bias show a maximum variability in the boundary layer with a maximum value of $14 \%$ (or $3.4 \times 10^{22} \mathrm{~m}^{-3}$ ) in the height interval $1.5-2.0 \mathrm{~km}$, decreasing above (smaller than $10 \%$ or $5 \times 10^{21} \mathrm{~m}^{-3}$ up to $4 \mathrm{~km}$ ). The mean relative RMS is found to increase with altitude up to $1.5-2 \mathrm{~km}$ with a limited variability above. The mean absolute RMS is found to decrease with altitude with a maximum value of $5 \times 10^{22} \mathrm{~m}^{-3}$ in the height interval $1.5-2.0 \mathrm{~km}$. The presence of smaller bias and RMS values in the upper levels, obtained when comparing airborne nadir-pointing DIAL instruments, suggest overall better performances of these systems above the PBL with respect to ground-based DIAL and Raman lidars (this is certainly the case if water vapour concentrations above the PBL are not appreciably exceeding climatological values). This consideration suggests the possibility to combine ground-based zenith-pointing Raman or DIAL systems with airborne DIAL systems to achieve measurements of the water vapour mixing ratio or number concentration profile with an overall bias smaller than $10 \%$ at all altitudes up $4 \mathrm{~km}$, thus determining a reduction of the overall measurement error in water vapour profiling based on the synergetic use of information coming from different lidars.

The mean bias is $3.93 \pm 0.58 \%\left((1.10 \pm 0.08) \times 10^{22} \mathrm{~m}^{-3}\right.$ or $\left.0.168 \pm 0.012 \mathrm{~g} \mathrm{~kg}^{-1}\right)$ in the altitude region $0.5-4.0 \mathrm{~km}$ a.s.l., with CNRS DIAL being wetter than DLR DIAL and the mean RMS deviation is $19.37 \pm 0.61 \%((2.10 \pm 0.08)$ $\times 10^{22} \mathrm{~m}^{-3}$ or $0.83 \pm 0.04 \mathrm{~g} \mathrm{~kg}^{-1}$ ).

\subsection{Overall Performances}

Based on the results reported in the previous section, it is possible to derive the overall bias values for the lidar systems involved in this intercomparison effort. We are using the approach proposed by Behrendt et al. (2007a,b) which is applicable when there is at least one instrument that carried out measurements which are comparable with those of all other lidar systems. This was the CNRS DIAL that, thanks to the several flights performed in the frame of the EUFAR Project H2OLidar, was able to guarantee multiple overpasses over all supersites equipped with ground-based lidar systems. This approach attributes equal weight on the data reliability of each instrument (as none of them can be a priori assumed to be more accurate than the others) and imposes the summation of all mutual biases between lidar pairs to be zero. This summation was extended to all lidar systems. Overall relative values for BASIL, BERTHA, IGN Raman lidar, UHOH DIAL, DLR DIAL, CNRS DIAL are found to be $-0.38 \%,-2.60 \%, 4.90 \%,-1.43 \%,-2.23 \%$ and $1.72 \%$, respectively. These results are summarized in Figure 26. All sensors were characterized by an overall bias smaller than $5 \%$.

\section{Summary and Conclusions}

In the framework of COPS, an intensive intercomparison effort involving six water vapour lidar systems was 

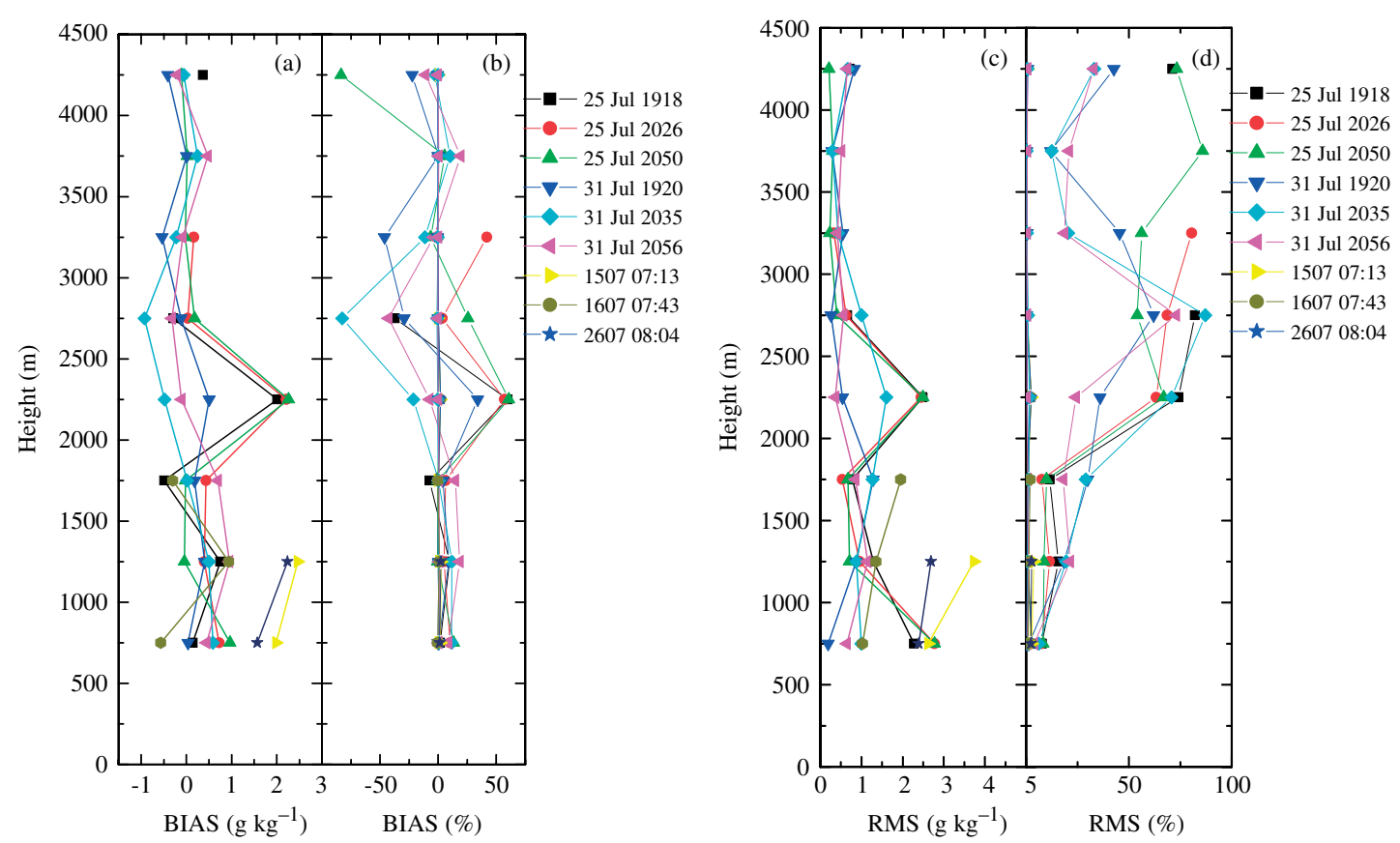

Figure 21. (a),(b) Bias and (c),(d) RMS deviations between IGN Raman lidar and the CNRS DIAL computed in the $500 \mathrm{~m}$ height intervals from 0.5 to $4.5 \mathrm{~km}$ a.s.l. for the nine profile-to-profile intercomparisons in Table VII. This figure is available in colour online at wileyonlinelibrary.com/journal/qj
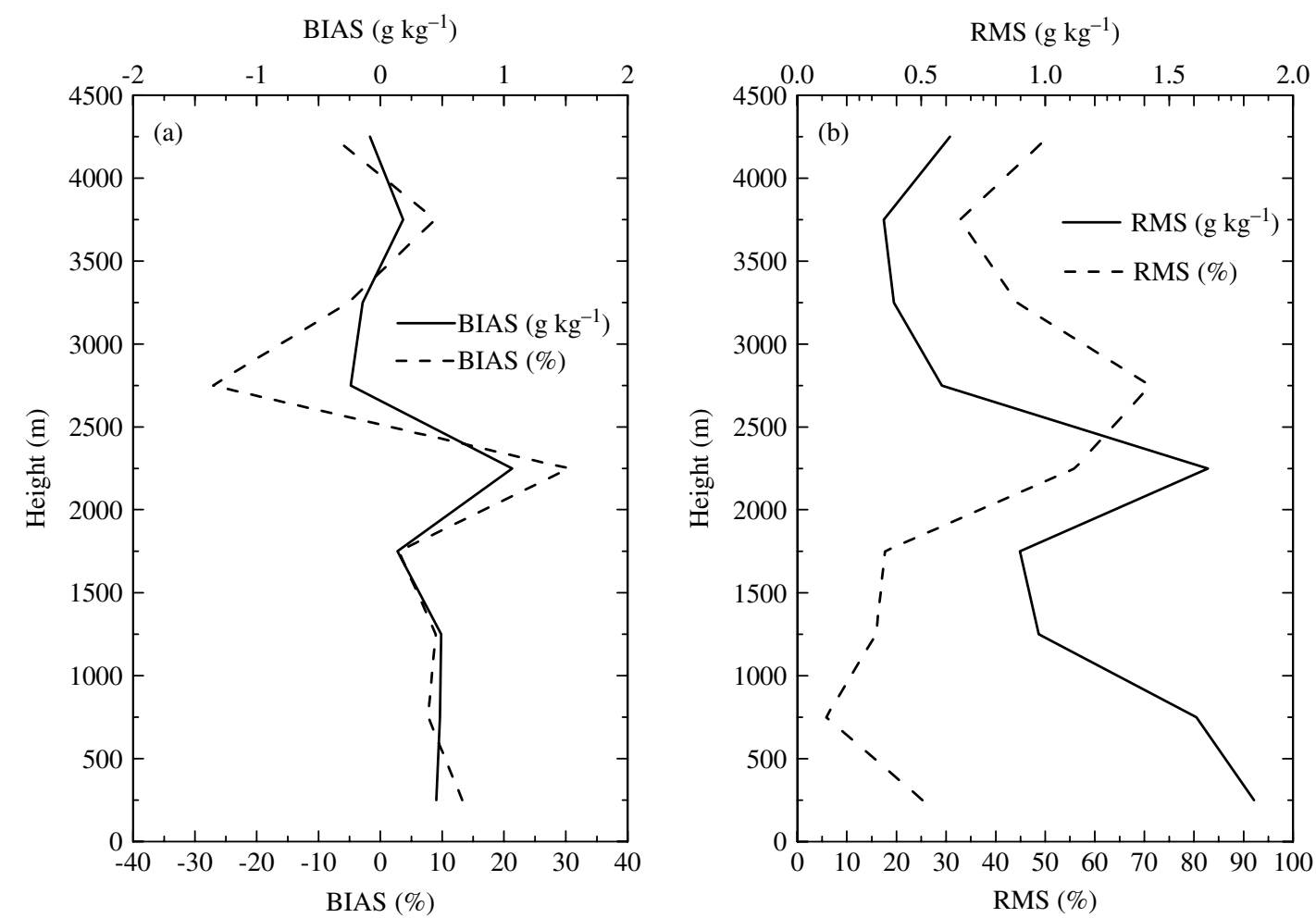

Figure 22. Profiles of mean bias (a) and RMS deviation (b) obtained using the nine IGN Raman lidar vs. CNRS DIAL profile-to-profile intercomparisons in Table VII.

carried out with the goal of providing accurate error estimates for these systems. A total of 50 profile-toprofile intercomparisons involving all possible lidar pairs were considered. The results illustrate the presence of low systematic errors (bias) - not exceeding 5\% - in the measurements carried out by the six water vapour lidar systems operated during COPS. Specifically, overall mean biases for the involved lidar systems are found to be: $-0.38 \%,-2.60 \%, 4.90 \%,-1.43 \%,-2.23 \%$ and $1.72 \%$ for BASIL, BERTHA, IGN Raman lidar, UHOH DIAL, DLR DIAL and CNRS DIAL, respectively. Additionally, based on the available comparisons between BASIL, the two airborne lidars and GPS, the biases are $-0.12 \%$, $-1.98 \%, 2.01 \%$ and $0.10 \%$ for BASIL, DLR DIAL, CNRS DIAL and GPS, respectively. Results obtained when combining information from different sets of sensors (six lidar systems on the one side, three lidars and a GPS station on the other side) lead to distinct estimates of 

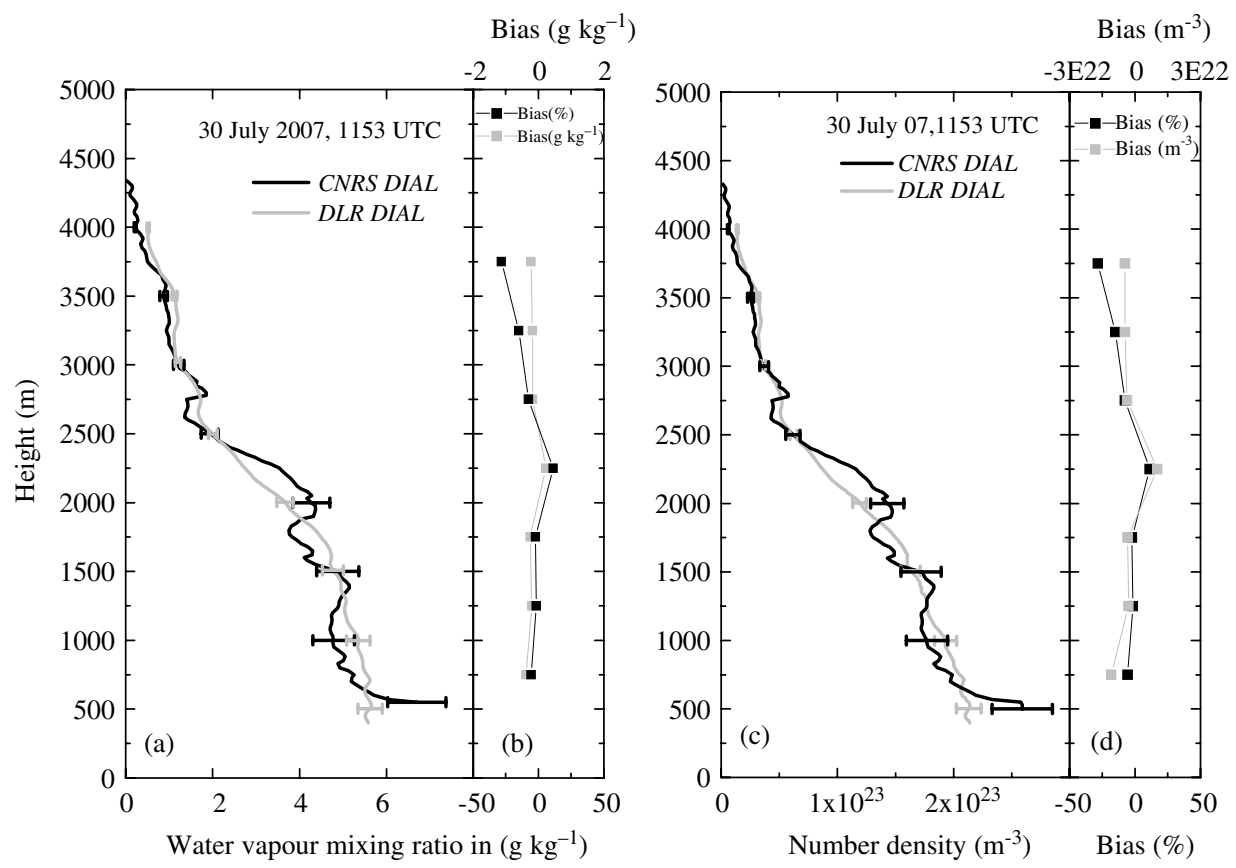

Figure 23. Comparison between CNRS DIAL and DLR DIAL at 1153 UTC on 30 July 2007 expressed in terms of (a) water vapour mixing ratio and (c) water vapour number density. Corresponding deviations, both absolute and relative, are shown in (b) and (d), respectively.
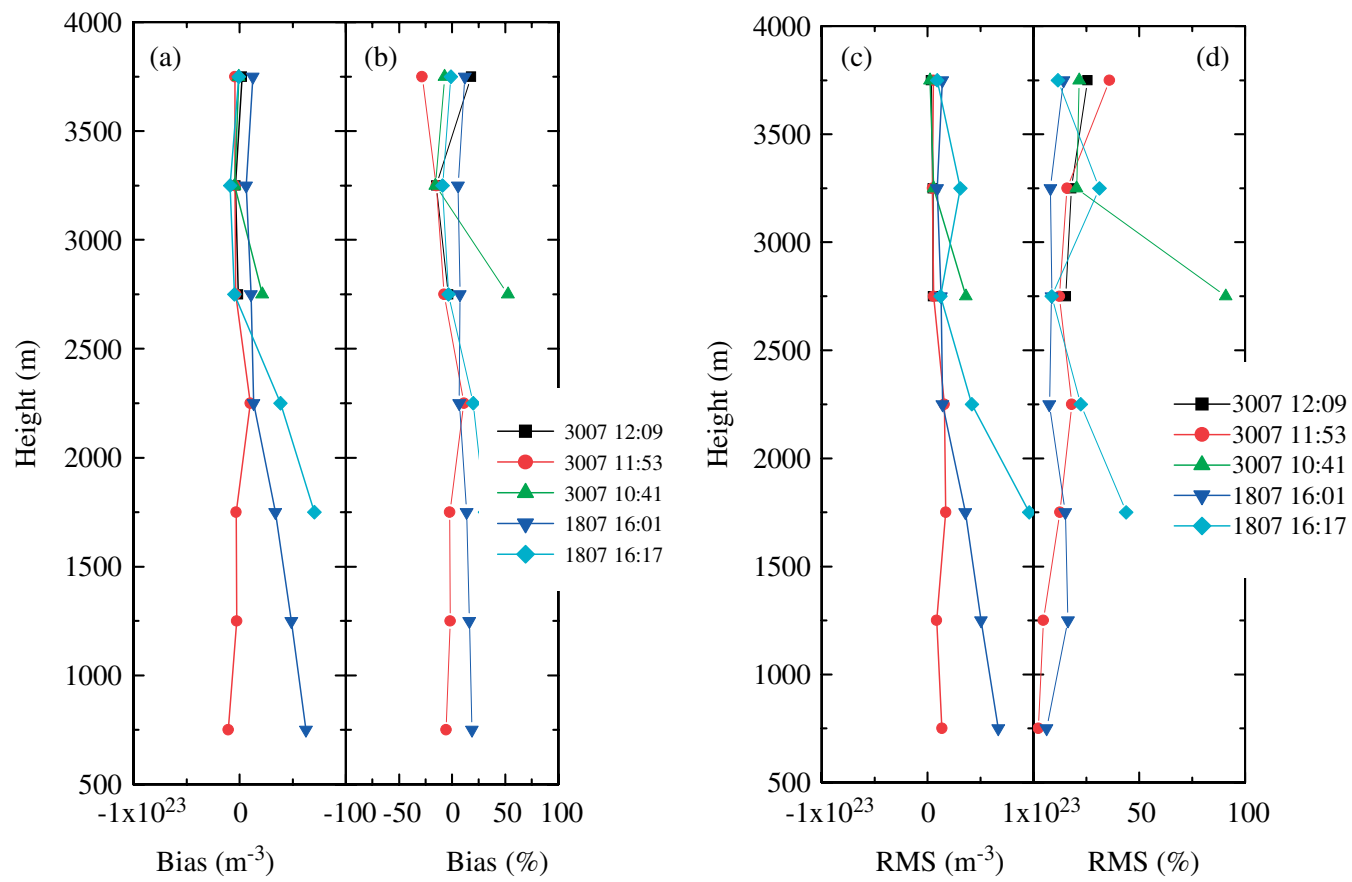

Figure 24. (a),(b) Bias and (c),(d) RMS deviations between CNRS DIAL and DLR DIAL computed in the $500 \mathrm{~m}$ height intervals from 0.5 to $4.0 \mathrm{~km}$ a.s.l. for the five profile-to-profile intercomparisons in Table VIII. This figure is available in colour online at wileyonlinelibrary.com/journal/qj

the overall relative bias for each sensor that are within $0.3 \%$.

There was no apparent dependency of the bias and RMS deviation on the spatial distance between the different lidar pairs with the airborne-to-ground-based intercomparisons. For all instrument pairs, small bias values (never exceeding $10 \%)$ are observed when overpasses of the airborne instruments are parallel to the Rhine valley as a result of the smaller heterogeneity of the water vapour field along the valley than in the direction perpendicular to it. The airborneto-airborne intercomparison results indicate that smaller bias values are present when comparing data collected along parallel flight tracks and coincident directions. Results also indicate that the combination of ground-based Raman or DIAL systems with airborne DIAL systems allow for measurements of the water vapour mixing ratio or number concentration profile with bias values smaller than $10 \%$ at all altitudes up to $4 \mathrm{~km}$.

Comparisons of data from airborne and ground-based lidars reveal the potential to (1) assess the representativeness error of vertically pointing ground-based lidar systems, (2) evaluate ground-based remote sensors in general that may be used for satellite data validation, and (3) assess 

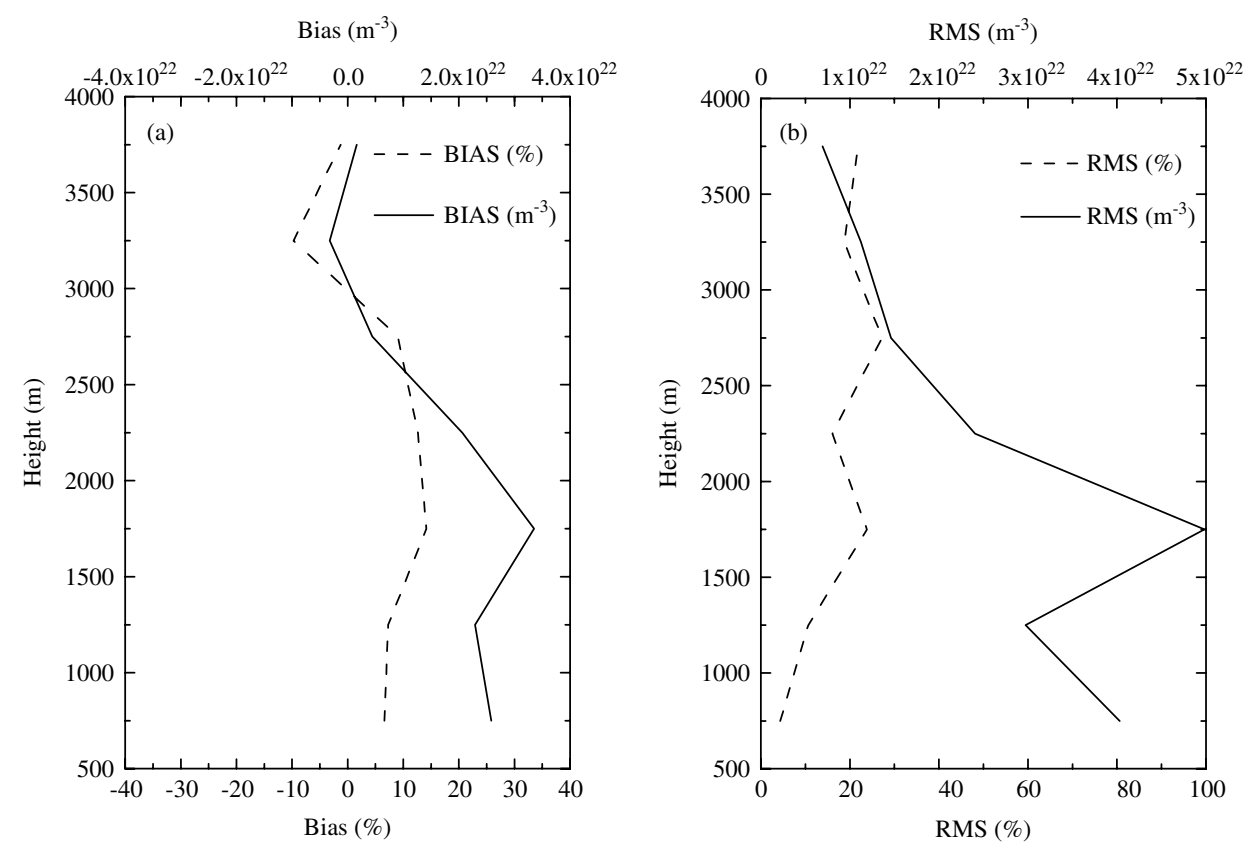

Figure 25. Profiles of mean bias (a) and RMS deviation (b) obtained using the five CNRS DIAL vs. DLR DIAL profile-to-profile intercomparisons in Table VIII.

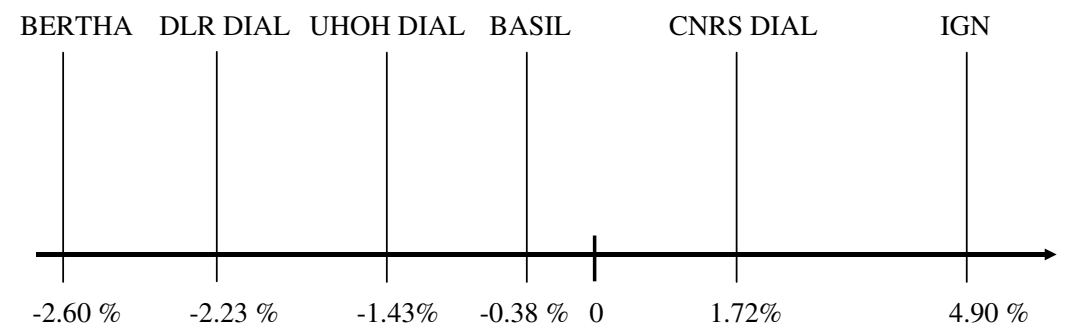

Figure 26. Resulting bias values after putting equal weight on all water vapour lidars.

the subgrid-scale variability of water vapour usually parametrized in mesoscale atmospheric models.

\section{Acknowledgements}

The authors wish to acknowledge the European Fleet for Airborne Research (EUFAR) programme of the $7^{\text {th }}$ Framework Programme for sponsoring some of the flight hours considered in this study. We also wish to thank the International Science Steering Committee of the Convective and Orographically-induced Precipitation Study for financial support of this activity.

\section{Appendix}

BASIL: Univ. of BASILicata Raman Lidar system BERTHA: Backscatter Extinction lidar Ratio Temperature Humidity profiling Apparatus

CNRS: Centre National de la Recherche Scientifique

COPS: Convective and Orographically-induced Precipitation Study

DLR: Deutsches Zentrum für Luft- und Raumfahrt

IGN: Institut Géographique National

IHOP_2002: International Water Vapor Project 2002

LEANDRE II: Lidar Embarque pour l'étude des Aerosols et des Nuages, de l'interaction Dynamique-Rayonnement et du cycle de l'Eau - Lidar for the study of
Aerosol-Cloud-Dynamics-Radiation interactions and of the Water cycle

SAFIRE: Service des Avions Français Instrumentés de Recherche sur l'Environnement UHOH: University of Hohenheim

\section{References}

Althausen D, Müller D, Ansmann A, Wandinger U, Hube H, Clauder E, Zörner S. 2000. Scanning 6-wavelength 11-channel aerosol lidar. J. Atmos. Oceanic Technol. 17: 1469-1482.

Barnes JE, Kaplan T, Vömel H, Read WG. 2008. NASA/Aura/Microwave Limb Sounder water vapor validation at Mauna Loa Observatory by Raman lidar. J. Geophys. Res. 113: D15S03, DOI:10.1029/2007JD008842.

Behrendt A, Wulfmeyer V, Di Girolamo P, Kiemle C, Bauer H-S, Schaberl T, Summa D, Whiteman DN, Demoz BB, Browell EV, Ismail S, Ferrare R, Kooi S, Ehret G, Wang J. 2007a. Intercomparison of water vapor data measured with lidar during IHOP 2002. Part I: Airborne to ground-based lidar systems and comparisons with chilled-mirror hygrometer radiosondes. J. Atmos. Oceanic Technol. 24: 3-21.

Behrendt A, Wulfmeyer V, Kiemle C, Ehret G, Flamant C, Schaberl T, Bauer H-S, Kooi S, Ismail S, Ferrare R, Browell EV, Whiteman DN. 2007b. Intercomparison of water vapor data measured with lidar during IHOP_2002. Part II: Airborne-to-airborne systems. J. Atmos. Oceanic Technol. 24: 22-39.

Behrendt A, Wulfmeyer V, Riede A, Wagner G, Pal S, Bauer H, Radlach M, Späth F. 2009. 'Three-dimensional observations of atmospheric humidity with a scanning differential absorption lidar.' In Remote sensing of clouds and the atmosphere XIV, Picard RH, Schäfer K, Comorón A, Kassianov EI, Mertens CJ (eds). Proc. SPIE 7475: DOI: $10.1117 / 12.83514$. 
Behrendt A, Pal S, Aoshima F, Bender M, Blyth A, Corsmeier U, Cuesta J, Dick G, Dorninger M, Flamant C, Di Girolamo P, Gorgas T, Huang Y, Kalthoff N, Khodayar S, Mannstein H, Träumner K, Wieser A, Wulfmeyer V. 2011. Observation of convection initiation processes with a suite of state-of-the-art research instruments during COPS IOP 8b. Q. J. R. Meteorol. Soc. 137(S1): 81-100, DOI: 10.1002/qj.758.

Bennett LJ, Blyth AM, Burton RR, Gadian AM, Weckwerth TM, Behrendt A, Di Girolamo P, Dorninger M, Lock S-J, Smith VH, Mobbs SD. 2011. Initiation of convection over the Black Forest mountains during COPS IOP 15a. Q. J. R. Meteorol. Soc. 137(S1): $176-189$.

Bhawar R, Bianchini G, Bozzo A, Calvello MR, Cacciani M, Carlotti M, Castagnoli F, Cuomo V, Di Girolamo P, Di Iorio T, Di Liberto L, di Sarra A, Esposito F, Fiocco G, Fuà D, Grieco G, Maestri T, Masiello G, Muscari G, Palchetti L, Papandrea E, Pavese G, Restieri R, Rizzi R, Romano F, Serio C, Summa D, Todini G, Tosi E. 2008. Spectrally resolved observations of atmospheric emitted radiance in the $\mathrm{H}_{2} \mathrm{O}$ rotation band. Geophys. Res. Lett. 35: L04812, DOI:10.1029/2007GL032207

Bösenberg J. 1998. Ground-based differential absorption lidar for water-vapor and temperature profiling: Methodology. Appl. Opt. 37: 3845-3860.

Bosser P, Bock O, Thom C, Pelon J. 2007. Study of the statistics of water vapor mixing ratio determined from Raman lidar measurements. Appl. Opt. 46: 8170-8180.

Bosser P, Bock O, Thom C, Pelon J, Willis P. 2010. A case study of using Raman lidar measurements in high-accuracy GPS applications. J. Geodesy 84: 251-265.

Browning KA, Morcrette CJ, Nicol J, Blyth AM, Bennett LJ, Brooks BJ, Marsham J, Mobbs SD, Parker DJ, Perry F, Clark PA, Ballard SP, Dixon MA, Forbes RM, Lean HW, Li Z, Roberts NM, Corsmeier U, Barthlott C, Deny B, Kalthoff N, Khodayar S, Kohler M, Kottmeier C, Kraut S, Kunz M, Lenfant J, Wieser A, Agnew JL, Bamber D, McGregor J, Beswick KM, Gray MD, Norton E, Ricketts HMA, Russell A, Vaughan G, Webb AR, Bitter M, Feuerle T, Hankers R, Schulz H, Bozier KE, Collier CG, Davies F, Gaffard C, Hewison TJ, Ladd DN, Slack EC, Waight J, Ramatschi M, Wareing DP, Watson RJ. 2007. The Convective Storm Initiation Project. Bull. Am. Meteorol. Soc. 88: 1939-1955.

Bruneau D, Quaglia P, Flamant C, Meissonnier M, Pelon J. 2001a. Airborne lidar LEANDRE II for water-vapor profiling in the troposphere. I: System description. Appl. Opt. 40: 3450-3461.

Bruneau D, Quaglia P, Flamant C, Pelon J. 2001b. Airborne lidar LEANDRE II for water-vapor profiling in the troposphere. II: First results. Appl. Opt. 40: 3462-3475.

Cahen C, Megie G, Flamant P. 1982. Lidar monitoring of the water vapor cycle in the troposphere. J. Appl. Meteorol. 21: 1506-1515.

Chaboureau J-P, Richard E, Pinty J-P, Flamant C, Di Girolamo P, Kiemle C, Behrendt A, Chepfer H, Chiriaco M, Wulfmeyer V. 2011 Long-range transport of Saharan dust and its radiative impact on precipitation forecast over western Europe. Q. J. R. Meteorol. Soc. 137(S1): 236-251.

Cooney JA. 1971. Comparisons of water vapor profiles obtained by radiosonde and laser backscatter. J. Appl. Meteorol. 10: 301-308.

Corsmeier U, Kalthoff N, Barthlott C, Behrendt A, Di Girolamo P, Dorninger M, Handwerker J, Kottmeier C, Mahlke H, Mobbs SD Norton EG, Wickert J, Wulfmeyer V. 2011. Processes driving deep convection over complex terrain: a multi-scale analysis of observations from COPS IOP 9c. Q. J. R. Meteorol. Soc. 137(S1): 137-155, DOI: 10.1002/qj.754.

Crook NA. 1996. Sensitivity of moist convection forced by boundary layer processes to low-level thermodynamic fields. Mon. Weather Rev. 124: $1767-1785$.

Di Girolamo P, Marchese R, Whiteman DN, Demoz BB. 2004. Rotational Raman lidar measurements of atmospheric temperature in the UV. Geophys. Res. Lett. 31: L01106, DOI:10.1029/2003GL018342.

Di Girolamo P, Behrendt A, Wulfmeyer V. 2006. Spaceborne profiling of atmospheric temperature and particle extinction with pure rotational Raman lidar and of relative humidity in combination with differential absorption lidar: Performance simulations, Appl. Opt. 45: 2474-2494.

Di Girolamo P, Summa D, Ferretti R. 2009a. Multparameter Raman lidar measurements for the characterization of a dry stratospheric intrusion event. J. Atmos. Oceanic Technol. 26: 1742-1762.

Di Girolamo P, Summa D, Lin R-F, Maestri T, Rizzi R, Masiello G. 2009b. UV Raman lidar measurements of relative humidity for the characterization of cirrus cloud microphysical properties. Atmos. Chem. Phys. 9: 8799-8811.

Di Girolamo P, Summa D, Bhawar R, Di Iorio T, Cacciani M, Veselovskii I, Kolgotin A. 2009c. 'Observation of a Saharan dust outbreak on 1-2 August 2007: Determination of size and microphysical particle parameters.' Pp 1-5 in Proceedings of the $8^{\text {th }}$ International Symposium on tropospheric profiling, S04-O06, Delft, The Netherlands, October 2009. Apituley A, Russchenberg HWJ, Monna WAA (eds).

Groenemeijer P, Barthlott C, Corsmeier U, Handwerker J, Kohler M, Kottmeier C, Mahlke H, Wieser A, Behrendt A, Pal S, Radlach M, Wulfmeyer V, Trentmann J. 2009. Observations of kinematics and thermodynamic structure surrounding a convective storm cluster over a low mountain range. Mon. Weather Rev. 137: 585-602.

Griaznov V, Veselovskii I, Di Girolamo P, Korenskii M, Summa D. 2007. Spatial distribution of doubly scattered polarized laser radiation in the focal plane of a lidar receiver. Appl. Opt. 46: 6821-6830.

Herold C. 2009. 'Wasserdampf- und Temperaturmessung mittels Lidar während COPS und SAMUM.' Diploma thesis, University of Leipzig, $80 \mathrm{pp}$.

Kiemle C, Wirth M, Fix A, Rahm S, Corsmeier U, Di Girolamo P. 2011. Latent heat fluxes over complex terrain from airborne water vapour and wind lidars. Q. J. R. Meteorol. Soc. 137(S1): 190-203, DOI: 10.1002/qj.757.

Kottmeier C, Kalthoff N, Corsmeier U, Barthlott C, Van Baelen J, Behrendt A, Behrendt R, Blyth A, Coulter R, Crewell S, Di Girolamo P, Dorninger M, Flamant C, Foken T, Hagen M, Hauck C, Höller H, Konow H, Kunz M, Mahlke H, Mobbs SD, Richard E, Steinacker R, Weckwerth T, Wieser A, Wulfmeyer V. 2008. Mechanisms initiating deep convection over complex terrain during COPS. Special issue on quantitative precipitation forecasting. Meteorol. Z. 17: 931-948.

Melfi SH. 1972. Remote measurements of the atmosphere using Raman scattering. Appl. Opt. 11: 1605-1610.

Melfi SH, Lawrence JD, McCormick MP. 1969. Observation of Raman scattering by water vapor in the atmosphere. Appl. Phys. Lett. 15: 295-297.

Mona L, Cornacchia C, D’Amico G, Di Girolamo P, Pappalardo G, Pisani G, Summa D, Wang X, Cuomo V. 2007. Characterization of the variability of the humidity and cloud fields as observed from a cluster of ground-based lidar systems. Q. J. R. Meteorol. Soc. 133(S3): 257-271.

Rotach MW, Ambrosetti P, Ament F, Appenzeller C, Arpagaus M, Bauer H-S, Behrendt A, Bouttier F, Buzzi A, Corazza M, Davolio S, Denhard M, Dorninger M, Fontannaz L, Frick J, Fundel F, Germann U, Gorgas T, Hegg C, Hering A, Keil C, Liniger MA, McTaggart-Cowan R, Marsigli C, Montaini A, Mylne K, Ranzi R, Richard E, Rossa A, Santos-Muñoz D, Schär C, Seity Y, Staudinger M, Stoll M, Volkert H, Walser A, Wang Y, Werhahn J, Wulfmeyer V, Zappa M. 2009. MAP D-PHASE: Real-time demonstration of weather forecast quality in the Alpine region. Bull. Am. Meteorol. Soc. 90: 1321-1336.

Rotunno R, Houze Jr RA, 2007. Lessons on orographic precipitation from the Mesoscale Alpine Programme. Q. J. R. Meteorol. Soc. 133: $811-830$.

Suortti TM, Kats A, Kivi R, Kämpfer N, Leiterer U, Miloshevich LM, Neuber R, Paukkunen A, Ruppert P, Vömel H, Yushkov V. 2008. Tropospheric comparisons of Vaisala radiosondes and balloonborne frost-point and Lyman- $\alpha$ hygrometers during the LAUTLOSWAVVAP Experiment. J. Atmos. Oceanic Technol. 25: 149-166.

Tesche M, Ansmann A, Müller D, Althausen D, Mattis I, Heese B, Freudenthaler V, Wiegner M, Esselborn M, Pisani G, Knippertz P. 2009. Vertical profiling of Saharan dust with Raman lidars and airborne HSRL in southern Morocco during SAMUM. Tellus 61B: 144-164.

Wagner G, Wulfmeyer V, Behrendt A. 2010. High-average-power Ti:Sapphire laser as transmitter of a scanning water-vapor DIAL. Appl. Opt., in preparation.

Warnecke G. 1997. Meteorologie und Umwelt. Springer-Verlag.

Weckwerth TM, Parsons DB, Moore JA, Koch SE, Demoz BB, LeMone MA, Flamant C, Geerts B, Wang J, Feltz WF. 2004. An overview of the International $\mathrm{H}_{2} \mathrm{O}$ Project (IHOP_2002) and some preliminary highlights. Bull. Am. Meteorol. Soc. 85: 253-277.

Werner C, Herrmann H. 1981. Lidar measurements of the vertical absolute humidity distribution in the boundary layer. J. Appl. Meteorol. 20: $476-481$.

Whiteman DN. 2003. Examination of the traditional Raman lidar technique. I: Evaluating the temperature-dependent lidar equations. Appl. Opt. 42: 2571-2592.

Whiteman DN, Demoz BB, Di Girolamo P, Comer J, Veselovskii I, Evans K, Wang Z, Sabatino D, Schwemmer G, Gentry B, Lin R-F, Behrendt A, Wulfmeyer V, Browell E, Ferrare R, Ismail S, Wang J. 2006. Raman lidar measurements during the International $\mathrm{H}_{2} \mathrm{O}$ Project. Part II: Case studies. J. Atmos. Oceanic Technol. 23: 170-183.

Wirth M, Fix A, Mahnke P, Schwarzer H, Schrandt F, Ehret G. 2009. The airborne multi-wavelength water vapor differential absorption lidar WALES: System design and performance. Appl. Phys. B 96: 201-213. 
Wulfmeyer V, Bösenberg J. 1996. Single-mode operation of an injectionseeded alexandrite ring laser for application in water vapor and temperature differential absorption lidar. Opt. Lett. 21: 1150-1152.

Wulfmeyer V, Bösenberg J. 1998. Ground-based differential absorption lidar for water-vapor profiling: Assessment of accuracy, resolution, and meteorological applications. Appl. Opt. 37: 3825-3844.

Wulfmeyer V, Walther C. 2001a. Future performance of ground-based and airborne water-vapor differential absorption lidar. I: Overview and theory. Appl. Opt. 40: 5304-5320.

Wulfmeyer V, Walther C. 2001b. Future performance of ground-based and airborne water-vapor differential absorption lidar. II: Simulations of the precision of a near-infrared, high-power system. Appl. Opt. 40: 5321-5336.

Wulfmeyer V, Bauer H-S, Grzeschik M, Behrendt A, Vandenberghe F, Browell EV, Ismail S, Ferrare RA. 2006. Four-dimensional variational assimilation of water vapor differential absorption lidar data: The first case study within IHOP_2002. Mon. Weather Rev. 134: 209-230.

Wulfmeyer V, Behrendt A, Bauer H-S, Kottmeier C, Corsmeier U, Blyth A, Craig G, Schumann U, Hagen M, Crewell S, Di Girolamo P, Flamant C, Miller M, Montani A, Mobbs SD, Richard E, Rotach MW,
Arpagaus M, Russchenberg H, Schlüssel P, König M, Gärtner V, Steinacker R, Dorninger M, Turner DD, Weckwerth T, Hense A, Simmer C. 2008. The Convective and Orographically-induced Precipitation Study: A research and development project of the World Weather Research Program for improving quantitative precipitation forecasting in low-mountain regions. Bull. Am. Meteorol. Soc. 89: $1477-1486$.

Wulfmeyer V, Behrendt A, Kottmeier C, Corsmeier U, Barthlott C, Craig GC, Hagen M, Althausen D, Aoshima F, Arpagaus M, Bauer HS, Bennett L, Blyth A, Brandau C, Champollion C, Crewell S, Dick G, Di Girolamo P, Dorninger M, Dufournet Y, Eigenmann R, Engelmann R, Flamant C, Foken T, Gorgas T, Grzeschik M, Handwerker J, Hauck C, Höller H, Junkermann W, Kalthoff N, Kiemle C, Klink S, König M, Krauss L, Long CN, Madonna F, Mobbs S, Neininger B, Pal S, Peters G, Pigeon G, Richard E, Rotach MW, Russchenberg H, Schwitalla T, Smith V, Steinacker R, Trentmann J, Turner DD, van Baelen J, Vogt S, Volkert H, Weckwerth T, Wernli H, Wieser A, Wirth M. 2011. The Convective and Orographically-induced Precipitation Study (COPS): the scientific strategy, the field phase, and first highlights. Q. J. R. Meteorol. Soc. 137(S1): 3-30, DOI: 10.1002/qj.752. 